\title{
Geometric Design of Suburban Roundabouts
}

\author{
Saša Ahac*(i) and Vesna Dragčević \\ Faculty of Civil Engineering, University of Zagreb, 10000 Zagreb, Croatia; vesna.dragcevic@grad.unizg.hr \\ * Correspondence: sasa.ahac@grad.unizg.hr
}

Definition: A modern roundabout is an intersection with a circulatory roadway at which the vehicle speed is low, and the traffic is continuous and circulating in one direction around the central island towards the exits at the approach legs. Modern roundabout design is an iterative process that is composed of the following steps: (1) the identification of the roundabout as the optimal traffic solution; (2) the definition of the number of lanes at the intersection based on the required capacity and the level of service; (3) the initial design of the roundabout geometry; (4) design vehicle swept path, the fastest path analysis, and visibility performance checks; and (5) detailed roundabout design if the results of the performance checks are in line with the design recommendations. Initial roundabout geometry design elements are not independent of each other; therefore, care must be taken to provide compatibility between them. An overview and a comparative analysis of the initial geometric design elements for suburban single-lane roundabouts defined in roundabout design guidelines and norms used in Croatia, Austria, France, the Netherlands, Germany, Serbia, and Switzerland is given in this entry.

Keywords: approach alignment; outer radius; circulatory roadway; apron; splitter island; roundabout entry; roundabout exit; longitudinal slope

Citation: Ahac, S.; Dragčević, V. Geometric Design of Suburban Roundabouts. Encyclopedia 2021, 1, 720-743. https://doi.org/10.3390/ encyclopedia1030056

Academic Editors: Raffaele Barretta, Ramesh Agarwal, Krzysztof Kamil Żur and Giuseppe Ruta

Received: 17 June 2021

Accepted: 4 August 2021

Published: 5 August 2021

Publisher's Note: MDPI stays neutral with regard to jurisdictional claims in published maps and institutional affiliations.

Copyright: (C) 2021 by the authors Licensee MDPI, Basel, Switzerland. This article is an open access article distributed under the terms and conditions of the Creative Commons Attribution (CC BY) license (https:// creativecommons.org/licenses/by/ $4.0 /)$.

\section{Introduction}

The development of modern roundabouts began in the 1960s in the United Kingdom with the adoption of the yield-at-entry rule, which gave the circulating traffic priority over entering traffic [1]. Modern roundabouts spread to other parts of Europe in the 1980s [2]. Intensive construction of roundabouts has begun in Europe in the last 30 years. European countries that stand out in the total number of roundabouts are France $(63,212)$, Spain $(36,762)$, and Italy $(30,917)[3]$, and states like the Netherlands, Sweden, Switzerland, Denmark, Finland, Germany, and Austria are also pursuing policies of mass roundabout construction.

Modern roundabout design is an iterative process, and it begins with the identification of the roundabout as the optimal traffic solution in the given conditions. The initial roundabout design refers to (1) defining the size of the intersection by selecting the outer radius, (2) laying the approach leg axes, and (3) defining the geometry of the design elements on roundabout entry and exit lanes, circulatory roadway, and central island. The initial design of the roundabout is usually followed by three performance checks: the examination of the design vehicle swept path, the fastest path analysis, and the visibility checks. If the results of these checks are not in line with the design recommendations, the geometry of the elements applied in the initial design phase is modified.

In this entry, guidelines for the initial design of individual geometric elements at a suburban single-lane roundabout, given in design guidelines and norms that are used in Croatia [4], Austria [5], France [6], the Netherlands [7,8], Germany [9], Serbia [10,11], and Switzerland [12-15], are presented. These documents are selected for the following reasons. Firstly, they all define the following geometric elements of suburban roundabouts: the outer radius, the circulatory roadway, the apron, the splitter islands, entry and exit design, and the longitudinal slopes of the approaches and/or the intersection plane. Secondly, 
the geography and the terrain in the countries these documents originate from are different, which affects the intersection design elements' dimensions and shapes. For instance, predominantly flat terrain can be found in the Netherlands, whereas predominantly mountainous terrain is found in Switzerland and Austria. At the same time, all terrain types are represented in France, Germany, Croatia, and Serbia. The third reason for the selection of the documents is the year in which they were issued, ranging from 1991, when Swiss guidelines were published, to the year 2014, when the newest edition of Croatian guidelines for suburban roundabouts was issued. Namely, this 23-year range was marked by the mass construction of roundabouts in all the above-mentioned countries, so we believe it would be interesting to observe whether and how roundabout design approaches changed in that period. The Federal Highway Administration (FHWA) guidelines are not included in this entry because the American design vehicles used in the swept path analysis (and, consequently, the dimensions of roundabout design elements) are larger than the vehicles that can be found on European roads. The reason the United Kingdom and Australian guidelines are omitted from this entry is the fact that the UK and Australian traffic drives on the left.

\section{Suburban Roundabout Design Elements}

Modern roundabout design is a process of determining the optimal balance between safety provisions, operational performance, and accommodation of the design vehicle. The criteria for the acceptability of roundabouts are usually defined in national guidelines and are adapted to the local circumstances [16]. These criteria include a functional criterion, capacity criterion, spatial criterion, design and technical criteria, traffic safety criterion, and economic criterion $[4,7,10]$. According to [4], to determine whether a roundabout is the best solution at a particular location, it is necessary to examine what the primary function of the planned intersection is (source-destination or transit traffic), what its role in the traffic network is, and its position concerning settlements (urban or suburban), as well as in the wider traffic network. The capacity criterion should examine whether the roundabout is an acceptable solution for the existing and expected circumstances, given the traffic flows and the distribution of traffic. The spatial criterion examines the availability of space for the geometric elements of the intersection. Design and technical criteria examine the geometry of the intersection, the position of the approaches, the number of the approaches, and the angle between the axes of the consecutive approaches. Traffic safety criteria should examine whether the roundabout in the existing conditions is a solution that guarantees safety to all road users. To achieve the required level of traffic safety, roundabouts must be recognizable in the traffic network and their geometry must force traffic to enter and circulate at a slow speed. Therefore, we should strive for the application of (1) uniform design solutions and (2) standardized design elements that provide sufficient deflection around the central island, with the minimal adaptation of these elements to the limitations arising from the specific location of the planned intersection.

According to the above-mentioned criteria, relevant parameters of roundabout design are spatial requirements and limitations, traffic load, design speed, and traffic flow structure. Based on these parameters, the geometric elements of roundabouts, which are described below, are defined. As these geometric elements are not independent of each other, care must be taken to provide compatibility between them to meet the design vehicle swept path requirements, overall safety, and capacity objectives. Geometric elements of modern suburban single-lane roundabouts are presented in Figure 1 and described below.

The central island is a raised physical barrier with a (usually) circular ground plan, placed in the center of the roundabout around which traffic circulates.

The circulatory roadway is a lane at which vehicles circle the central island in a counterclockwise direction. Vehicles at a circulatory roadway have priority over vehicles entering a roundabout.

The outer radius is the radius of the outer edge of the circulatory roadway. It is the sum of the central island radius and the circulatory roadway width. 


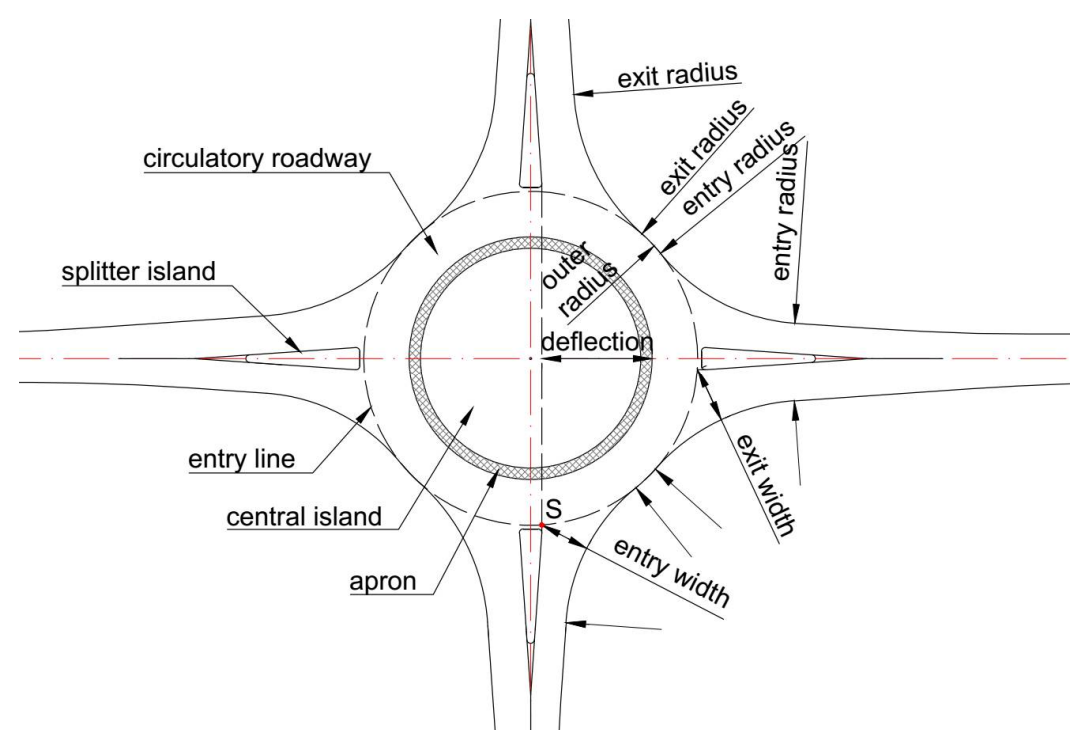

Figure 1. The geometric elements of single-lane roundabouts.

The apron is the traversable part of the central island that may be needed to allow long vehicles to negotiate a roundabout. It differs from the circulatory roadway by the cross slope, material used for the final layer, and/or color.

The entry line marks the point of entry into the circulatory roadway. This line is an extension of the circulatory roadway edge line, and it functions as a yield or give-way line: Entering vehicles must yield to any circulating traffic coming from the left before crossing this line into the circulatory roadway.

The splitter island is a raised or drawn element on the roundabout approach intended to channel traffic flows at the entrance and exit of the intersection.

The roundabout entry is bounded by a curb or edge of pavement consisting of a curve leading into the circulatory roadway. This curve is tangential to the outside edge of the circulatory roadway.

The roundabout exit is bounded by a curb or edge of pavement consisting of a curve leading away from the circulatory roadway. This curve is tangential to the outside edge of the circulatory roadway. The exit radii are usually larger than the entry radii to minimize the likelihood of congestion and crashes at the exits.

The entry width is the shortest distance between the intersection of the line connecting the vertices of the opposite dividing islands and the entrance line (point $S$ ) and the right curb or edge of the pavement at the entrance to the roundabout.

The deflection is the distance between a straight line joining the vertices of opposite dividing islands and its parallel that is tangent to a central island.

\subsection{The Approach Alignment}

Roundabout approach alignment affects the curvature of the vehicle's trajectory when passing through the intersection, the accommodation of the design vehicles, and the viewing angles on the adjacent approaches. The optimal design of a roundabout depends on the size and position of the roundabout concerning the approach alignment.

The standard approach alignment on suburban roundabouts is radial, where the approach axes intersect in the center of the outer radius of the intersection (Figure 2a). This alignment allows the appropriate design of the geometric elements of single-lane roundabouts, which ensures low vehicle velocity. The radial alignment of the approaches ensures the visibility of intersections in the traffic network and minimizes the need to modify the geometric elements on the approaches. An alternative to radial alignment is a displacement of the intersection approach axes, which can be carried out either by the displacement of this intersection to the left of the center of the outer radius (Figure 2b), or by laying the approach axes so they intersect to the right of the center of the outer radius of 
the roundabout (Figure 2c). Displacement to the left increases the curvature of the entrance path of the vehicle, i.e., provides better speed control at the intersection. Displacement to the right (Figure 2c) should be avoided, as it does not provide sufficient curvature of the vehicle entry path, i.e., this alignment allows vehicles to enter the intersection too fast, which increases the risk of collision.

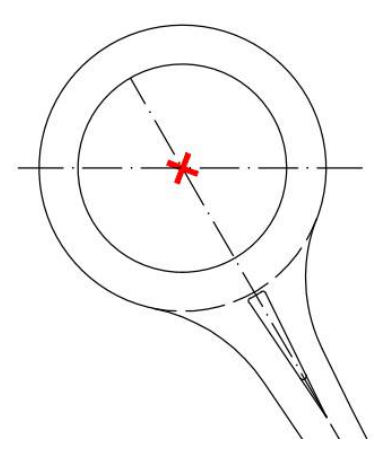

(a)

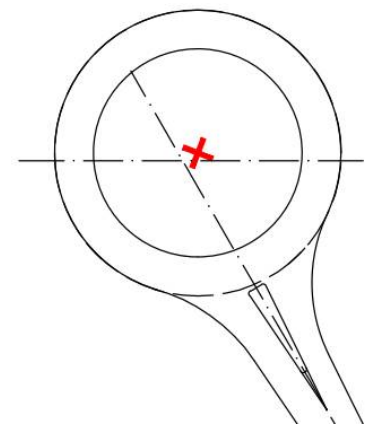

(b)

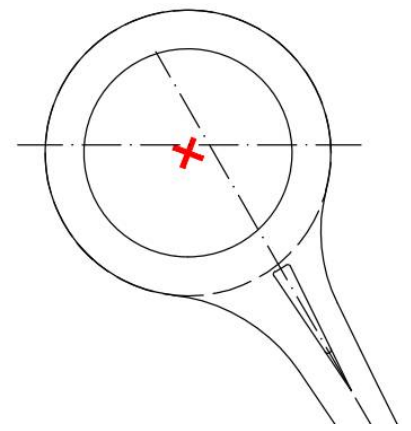

(c)

Figure 2. The approach alignment variants according to [8]: (a) radial alignment geometric elements of single-lane roundabouts, (b) displacement to the left, and (c) displacement to the right. The red " $\times$ " marks the center of the roundabout outer radius.

The optimal angle between the approach axes is $90^{\circ}$. If the axes intersect at an angle significantly greater than $90^{\circ}$, the permitted driving speed may be exceeded for right turns. If the approach axes intersect at an angle significantly less than $90^{\circ}$, the required accommodation of long vehicles is disabled. Increasing the radius of curve at the right edge of the pavement at the entrance to such intersections (which must be done to accommodate long vehicles) increases the entrance width, which reduces the level of intersection safety, as it can result in higher vehicle velocity. Reducing the angle between the approach axis results in the need to increase the outer radius of the roundabout to meet the conditions of the design vehicle swept path and speed requirements at an intersection.

\subsection{The Outer Radius}

At single-lane roundabouts, the size of the outer radius depends on the spatial requirements and limitations, the number and alignment of the approaches, the traffic requirements of the design vehicle swept path (the outer radius must allow the passage of the design vehicle), and the design speed (the curvature of the vehicle's trajectory must limit driving speeds to ensure low vehicle speeds when passing through the intersection).

When examining the swept path of the design vehicles, it must be demonstrated that the design vehicle can pass through the intersection using the available lane width while ensuring minimum lateral clearance (usually between 25 and $50 \mathrm{~cm}$ wide) and respecting road markings. The design vehicle is a vehicle of a certain type and dimensions that characterize a certain group of vehicles and fully complies with the legal regulations on vehicle dimensions, i.e., international recommendations. Design vehicles are used to examine the possibility of vehicles of a certain category passing through an intersection. They are most often selected according to the position of the intersection in the road network, depending on the structure and category of vehicles that appear on the observed section of the road.

The recommended and limit values of the outer radii at suburban single-lane roundabouts listed in the analyzed documents are shown in Figure 3. 


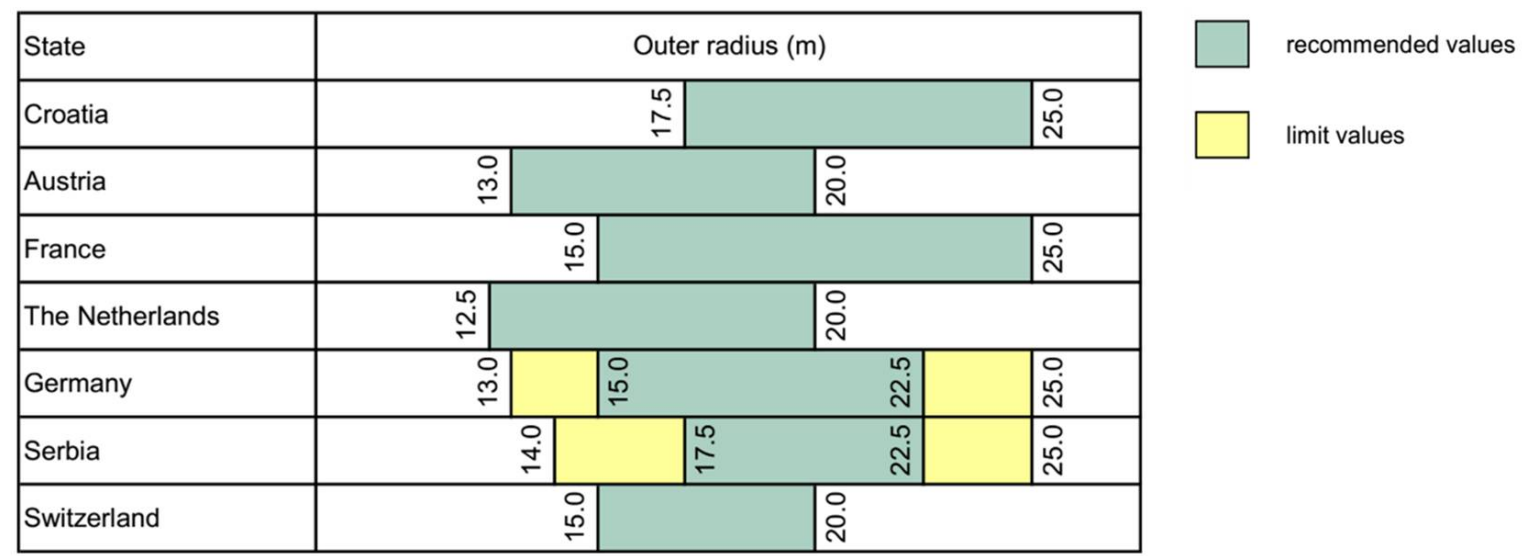

Figure 3. Recommended outer radii for single-lane roundabouts according to [4-12].

\subsection{The Circulatory Roadway}

At single-lane roundabouts, the width of the circulatory roadway depends on the swept path requirements of the design vehicle, whereas the cross slope of the circulatory roadway depends on surface drainage and topographic conditions. The cross slope of the circulatory roadway is usually directed towards the outside of the intersection. Such a direction is suitable for the following reasons: It increases the safety of intersections by raising and improving the visibility of the central island, it reduces vehicle speed on the path around the central island, it minimizes cross slope changes at the entry and exit, and it helps surface drainage.

According to [4], the minimal width of a circulatory roadway is determined based on the swept path of a selected two-axle design vehicle for driving in a full circle. Recommended values for the width of the circulatory roadway range from 4.5 to $6.0 \mathrm{~m}$, and the recommended value of the cross slope of the circulatory roadway according to [5] is smaller than or equal to $2.5 \%$.

According to [5], the width of the circulatory roadway ranges from 6.5 to $9.0 \mathrm{~m}$. When determining the width of the circulatory roadway, it is necessary to ensure the deflection of the vehicle driving around the central island. If sufficient deflection is not achieved, it is necessary to plan the construction of a larger central island with an apron. The recommended value of the cross slope of the circulatory roadway according to [5] is $2.5 \%$, where the slope is directed towards the outer edge of the intersection, as shown in Figure 4a. If, due to topographic conditions, it is necessary to construct an intersection with a longitudinal slope greater than $2.5 \%$, the circulatory roadway is placed in one plane, with a slope less than or equal to $4 \%$ (Figure $4 \mathrm{~b}$ ). The minimum value of the cross slope is $1.5 \%$, which ensures sufficient surface drainage of the intersection.

According to [6], a circulatory roadway should not look like a one-way multi-lane road, but a single lane of sufficient width to ensure the accommodation of the design vehicle. On single-lane roundabouts, the width of the circulatory roadway depends on the outer radius and the width of the widest entrance to the intersection. The width of the circulatory roadway is fixed and $20 \%$ larger than the widest entrance, with the minimum width of the circulatory roadway being $6 \mathrm{~m}$ and the usual width $7 \mathrm{~m}$. The use of an 8 -m-wide circulatory roadway is justified at roundabouts where the design vehicle is a tractor with a semi-trailer. The cross slope of the circulatory roadway is also constant along its entire length and its value can range from 1.5 to $2 \%$. The cross slope is directed towards the outer edge of the intersection. These values do not apply to roundabouts on steep slopes, which should in any case be avoided. Additionally, the maximum cross slope of the roundabout is $3 \%$. 


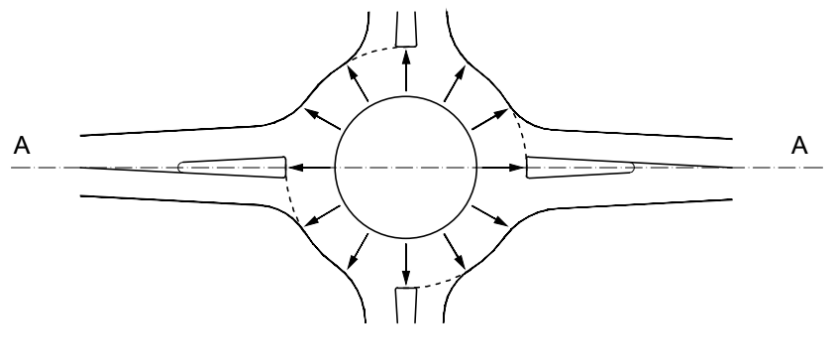

A - A

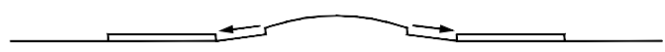

(a)

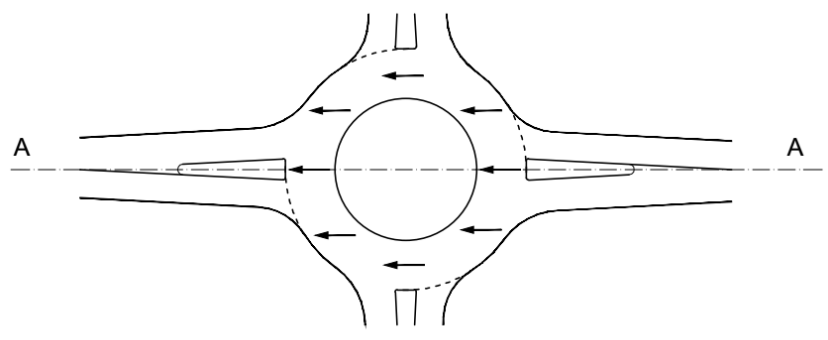

A - A

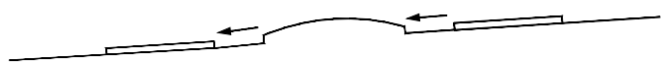

(b)

Figure 4. Circulatory roadway cross slope according to [5]: (a) recommended cross slope direction and (b) circulatory roadway in one plane. Slope direction is represented by the arrows.

According to $[7,8]$, the standard width of the circulatory roadway at single-lane suburban roundabouts is $5.25 \mathrm{~m}$, regardless of the dimensions of the design vehicle. It is noted that these standard values must not be adopted as absolute: The width of the circulatory roadway must meet the requirements of the design vehicle, but also the condition of limiting the speed of the vehicle passing through the intersection. Circulatory roadway width must be fixed along the entire length of the lane. Figure 5 shows the values of the width of the circulatory roadway (" $\mathrm{B}$ ") as a function of the outer and inner radius of the roundabout (" $\mathrm{R}_{\mathrm{bu}}$ " and " $\mathrm{R}_{\mathrm{bi}}$ ") for single-lane roundabouts. The cross slope of the circulatory roadway according to [7] is 2.0 to $2.5 \%$ and is directed towards the outer edge of the roundabout.

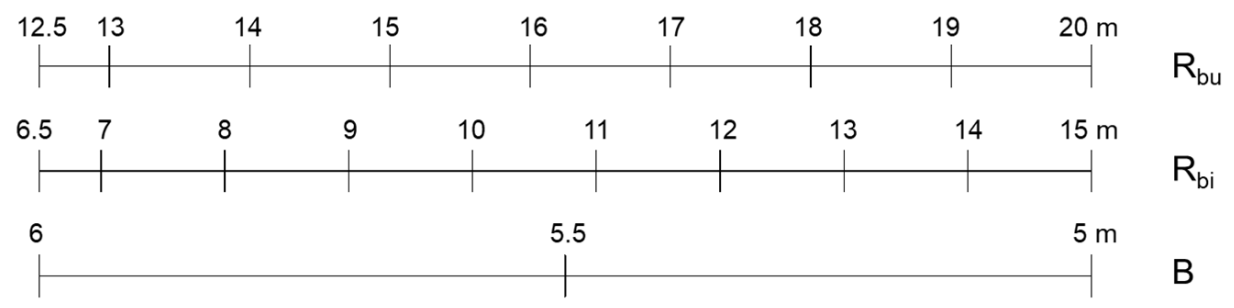

Figure 5. Circulatory roadway width (" $\mathrm{B}$ ") depending on the outer and inner radius (" $\mathrm{R}_{\mathrm{bu}}$ " and "R $\mathrm{bi}^{\prime \prime}$ ) [8].

According to [9], the circulatory roadway, together with the apron, which is not included in the width of the circulatory roadway, forms a circular ring of intersection (width " $\mathrm{B}_{\mathrm{k}}$ "). The circulatory roadway is of constant width and a constant cross slope. The circulatory roadway width depends on the size of the outer radius-the widths of the circular ring of intersection (" $\mathrm{B}_{\mathrm{k}}$ ") for single-lane roundabouts depending on the size of the outer radius are given in Table 1. For suburban roundabouts, the widths of the circular ring of intersection (" $\mathrm{B}_{\mathrm{k}}$ ") shown in the table correspond to the widths of the circulatory roadway, since the aprons are not constructed at these intersections. At suburban intersections with increased truck traffic, it is possible to apply larger widths of the circulatory roadway than those given in the table. The cross slope of the circulatory roadway is directed towards the outer edge of the intersection and must be at least $2.5 \%$ to ensure proper surface drainage of the pavement. 
Table 1. Circular ring width (" $\mathrm{B}_{\mathrm{k}}$ ") depending on the outer radius [9].

\begin{tabular}{cc}
\hline Outer Radius $(\mathbf{m})$ & Circular Ring Width “ $\mathbf{B}_{\mathbf{k}}{ }^{\text {” }} \mathbf{( m )}$ \\
\hline 13 & 9.0 \\
15 & 8.0 \\
17.5 & 7.0 \\
$\geq 20$ & 6.5 \\
\hline
\end{tabular}

According to [10], the width of the circulatory roadway (" $\mathrm{b}_{\mathrm{k}}$ ") arises from the swept path requirements of the design vehicle and the driving conditions. It can be standardized to some extent for typical suburban road network conditions for single-lane and two-lane roundabouts. The standard widths of the roundabout (" $b_{k}$ ") for single-lane roundabouts (Figure 6) are defined depending on the diameter of the inscribed circle of a roundabout $(" \mathrm{D}$ ") and include marginal strips that are $0.20 \mathrm{~m}$ wide.

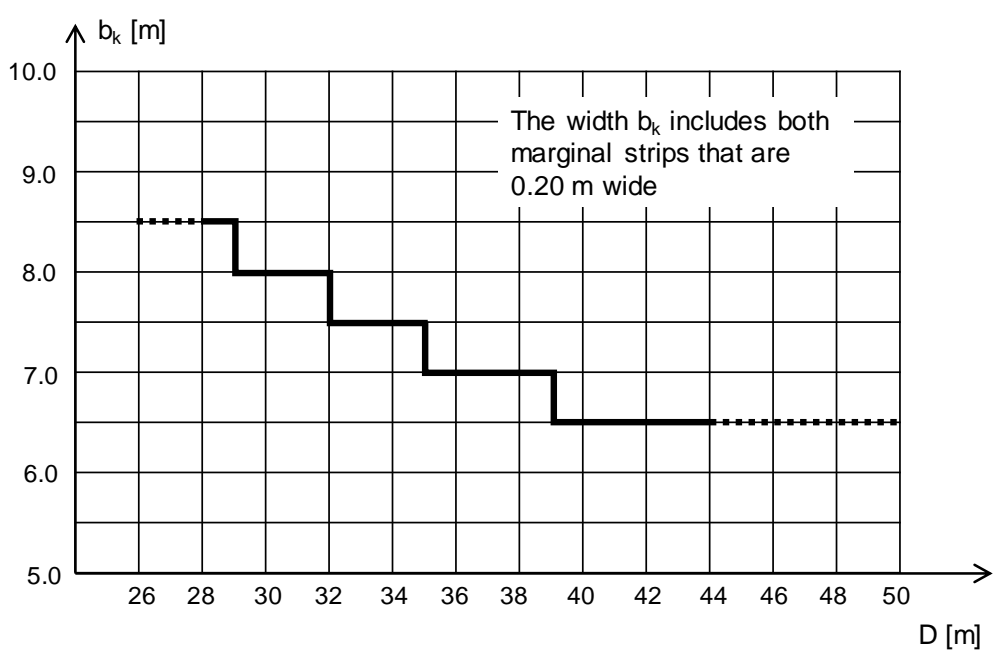

Figure 6. Circulatory roadway width (" $\mathrm{b}_{\mathrm{k}}$ ”) for single-lane roundabouts [10].

According to [10], the standard cross slope of the circulatory roadway is $2.5 \%$. The cross slope is directed towards the outer edge of the intersection. The maximum cross slopes of the circulatory roadway (" $\mathrm{i}_{\mathrm{p}}$ ") as a function of the slope of the intersection plane $\left(" \mathrm{i}_{\mathrm{Nkr}}{ }^{\prime \prime}\right)$ is shown in Table 2. At the same time, the largest total slope is $4 \%$ [10].

Table 2. Circulatory roadway slope [10].

\begin{tabular}{cc}
\hline Longitudinal Slope "i $\mathbf{i}_{\mathbf{N k r}}$ " (\%) & Maximum Cross Slope " $\mathbf{i}_{\mathbf{p}}$ " (\%) \\
\hline $0<\mathrm{i}_{\mathrm{Nkr}} \leq 2.5$ & -2.5 \\
$2.5<\mathrm{i}_{\mathrm{Nkr}} \leq 4.0$ & 2.5 \\
$4.0<\mathrm{i}_{\mathrm{Nkr}} \leq 5.7$ & 4.0 \\
\hline
\end{tabular}

According to [12], the total width of the circulatory roadway and apron depends on the outer diameter of the roundabout and the swept path conditions of the design vehicle. Figure 7 shows a diagram used to determine the minimum widths depending on the outer diameter of the intersection. These widths are determined by swept path analysis for the design vehicle defined according to [13]. These widths do not include lateral clearances. Larger circulatory roadway widths should be avoided for safety reasons. It is recommended that for a width of the circulatory roadway greater than $5.5 \mathrm{~m}$, the apron be used, intended only for tractors with semi-trailers and trucks with trailers. The maximum cross slope of the circulatory roadway is $5 \%$ (exceptionally $7 \%$, in demanding topographic conditions). The minimum cross slope of the circulatory roadway is limited to $3 \%$ due to the pavement surface drainage conditions. 


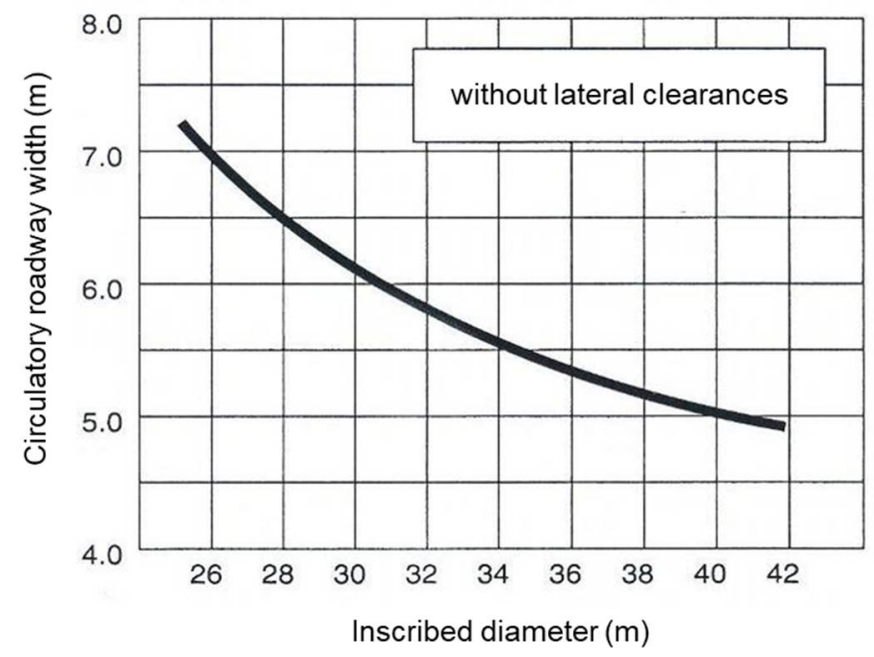

Figure 7. Minimum circulatory roadway width (together with apron width) depending on the roundabout inscribed diameter [12].

Standard circulatory roadway widths for suburban single-lane roundabouts listed in the analyzed documents are shown in Figures 8 and 9. The values in Figure 8 refer to single-lane roundabouts with and without the apron, the application of which depends on the choice of design vehicle: The apron is intended exclusively to accommodate trucks (tractors with semi-trailers, trucks with trailers).

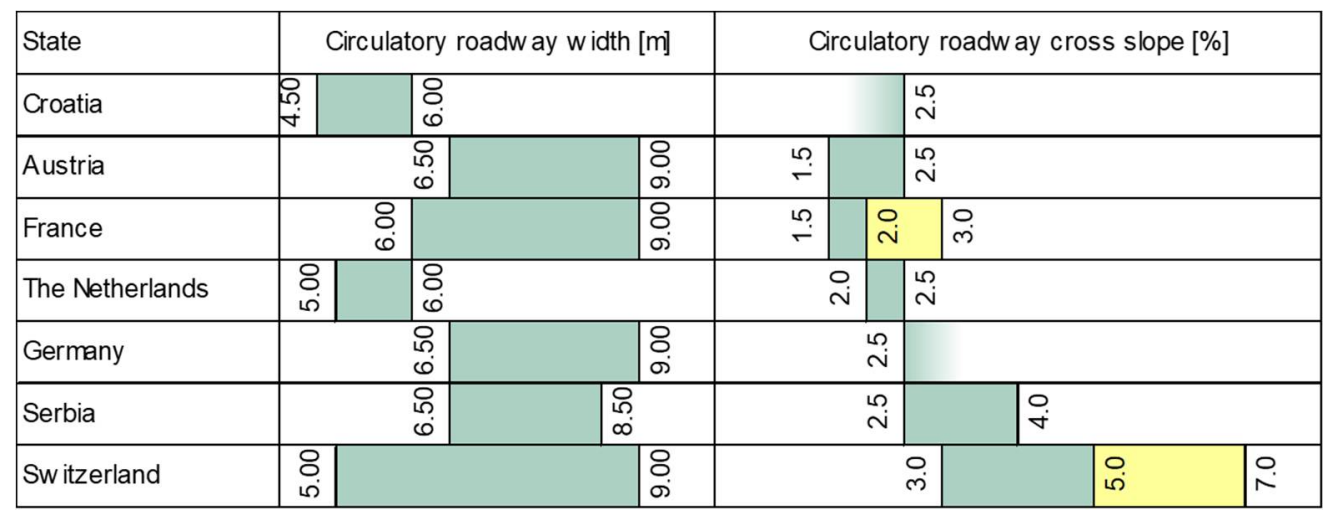

recommended values

limit values

Figure 8. Recommended and limit circulatory roadway widths and cross slope according to [4-12].

According to the data shown in Figure 9, the highest values of the width of the circular lane are defined by the German guidelines and the lowest values by the Dutch guidelines. The width of the circular lane determined by the diagrams shown in Figure 9 is usually rounded up to a larger $0.25 \mathrm{~m}$. According to [9-12], the width of a circular lane includes an additional element-an apron, the transit edge of the central island, described below.

\subsection{The Apron}

At roundabouts, to ensure the low driving speed of passenger cars while meeting the traffic conditions of long vehicles, it is sometimes necessary to provide an apron on the edge of the central island.

According to [4], the apron width is determined based on the swept path of a design vehicle for driving in a full circle. For suburban roundabouts, this design vehicle is a $16.5 \mathrm{~m}$-long tractor with a semi-trailer.

According to [5], the apron is constructed only when the required deflection cannot be achieved due to the conditions of the swept path for the design vehicle. The widths and other design features of the apron are not described in the document. 


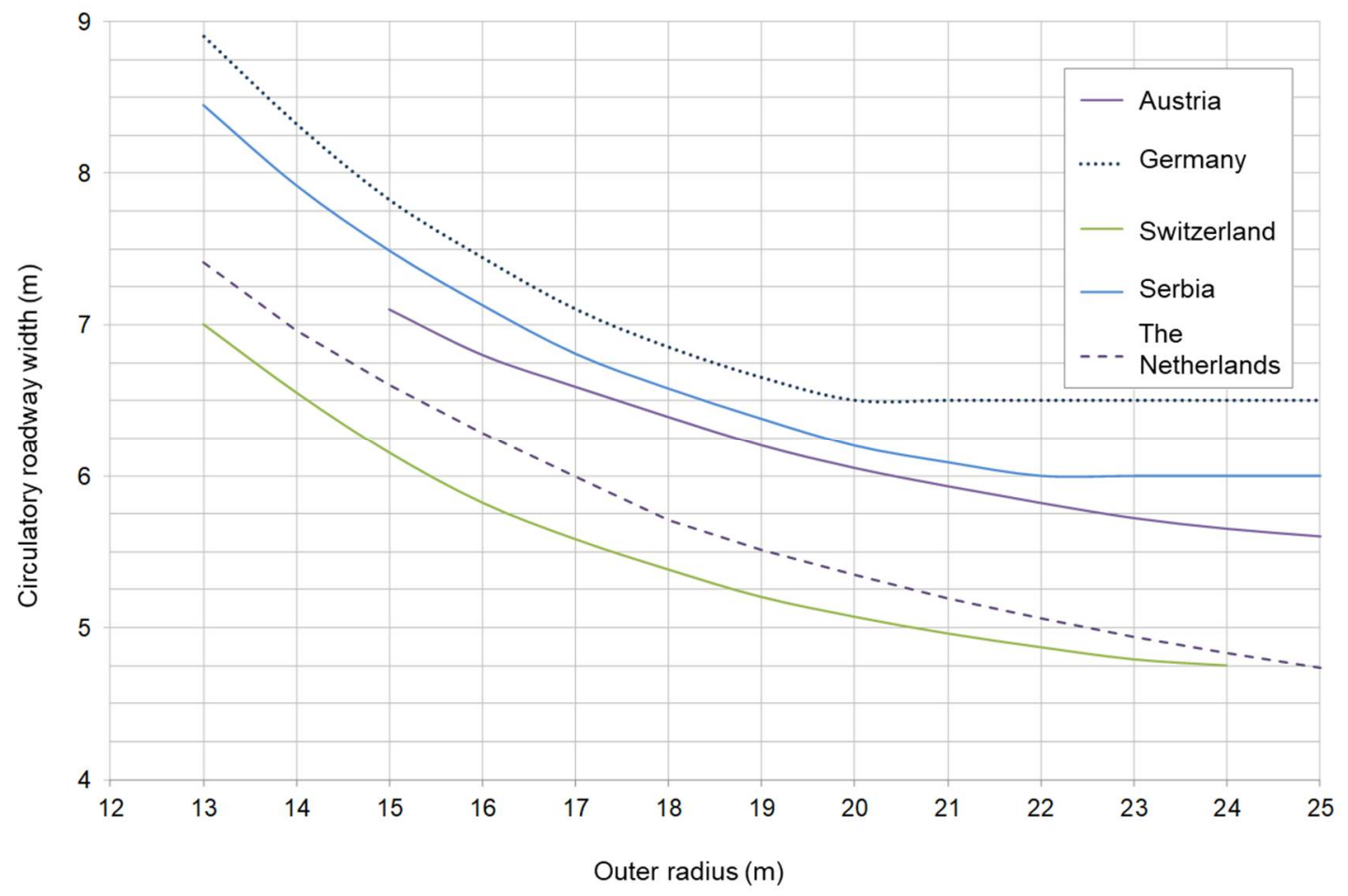

Figure 9. Standard circulatory roadway widths for suburban single-lane roundabouts [8,11].

According to [6], the apron is constructed at roundabouts with an outer radius in the range of 12 to $15 \mathrm{~m}$. The apron width is in the range of 1.5 to $2.0 \mathrm{~m}$ (Figure 10). The apron may also be constructed at roundabouts with an outer radius larger than $15 \mathrm{~m}$ if convoys of special cargo pass through the intersection. The cross slope of the apron is directed towards the outer edge of the intersection and ranges from 4 to $6 \%$. It is recommended to raise the apron above the circulatory roadway by applying a low curb $(3 \mathrm{~cm}$ high) and to make a final layer of stone cubes so that the edge is visible in both day and night driving conditions.

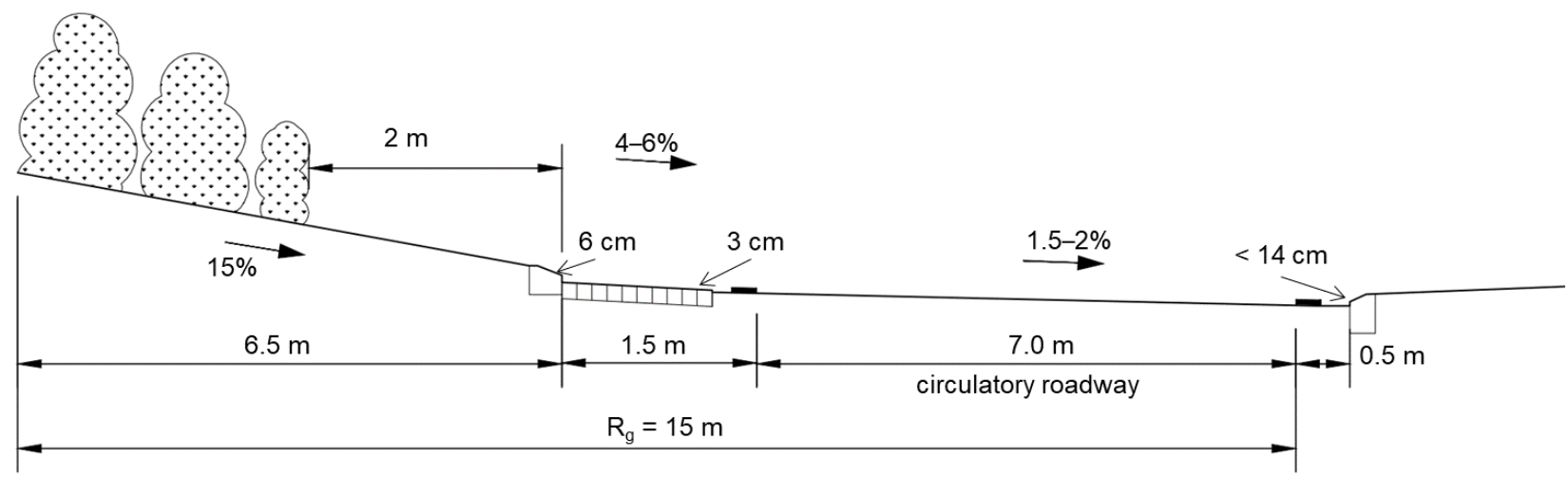

Figure 10. Standard circulatory roadway cross-section for roundabouts with an outer radius of $15 \mathrm{~m}$, according to [6].

According to $[7,8]$, the apron width depends on the design vehicle and the combination of dimensions of the remaining geometric elements of the roundabout. The standard cross slope of the apron is $1 \%$. The apron is constructed with a low curb with a slight slope (the height difference compared to the circulatory roadway pavement is $5 \mathrm{~cm}$ at most) and with a paved surface (cubes) [8]. The standard apron width at suburban single-lane roundabouts is $1.5 \mathrm{~m}$. Depending on the dimensions of the design vehicle, the apron width is $3 \mathrm{~m}$ (for a vehicle $22 \mathrm{~m}$ long) or $4 \mathrm{~m}$ (for a vehicle $27 \mathrm{~m}$ long) [7].

According to [9], aprons are not constructed on suburban roundabouts. 
According to [10], the inner edges of the circulatory roadway are formed by applying elements of a different structure (e.g., paving elements, a small cube). The central island is shaped with one hog curve at the center of the island and two sag curves at the outer edge of the island (Figure 11), and the slope of the tangents between these elements is $4 \%$. The document in question, which refers to suburban roundabouts, does not envisage the construction of the apron. According to [11], the apron width is determined based on swept path analysis for the design vehicle, with the minimum apron width being $1 \mathrm{~m}$. This element is raised above the circulatory roadway by $3 \mathrm{~cm}$, and its cross slope is $4 \%$ ( $3 \%$ in exceptional cases).

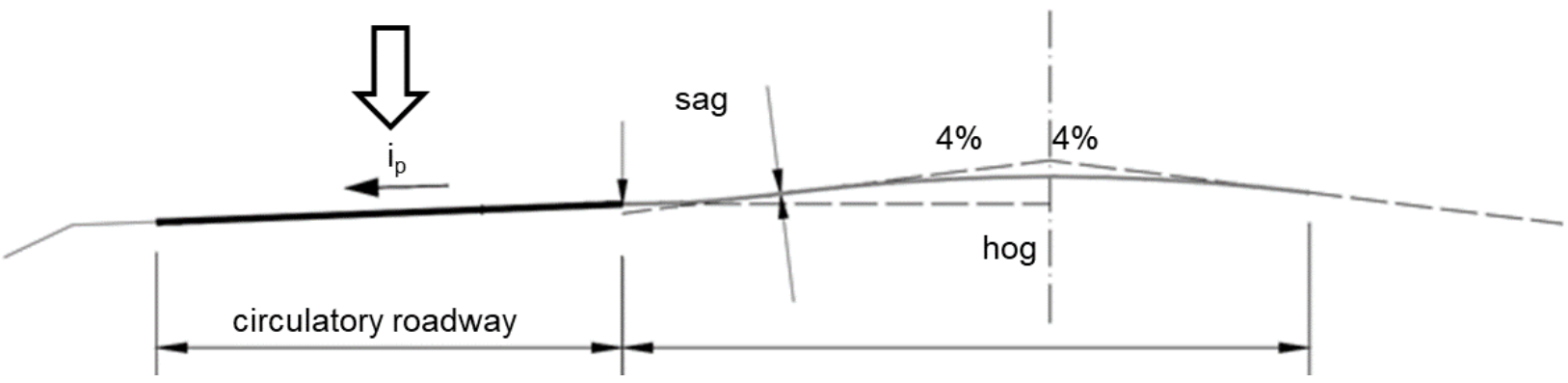

Figure 11. Central island design [10].

According to the standard [12], for circulatory roadway widths greater than $5.5 \mathrm{~m}$, it is recommended to use the apron, intended only for trucks. The design of the apron is not defined in the specified standards. According to [15], the usual width of the apron (paved with stone cubes) at single-lane roundabouts is $1.5-2.0 \mathrm{~m}$.

The standard widths and cross slopes of the apron at suburban single-lane roundabouts listed in the considered documents are shown in Table 3.

Table 3. Apron width and cross slope according to [4-12].

\begin{tabular}{ccc}
\hline State & Apron Width $(\mathbf{m})$ & Apron Cross Slope (\%) \\
\hline Croatia & defined based on the design vehicle swept path & not defined \\
Austria & defined based on the design vehicle swept path & not defined \\
France & $1.5-2.0$ (for outer radius between 12 and $15 \mathrm{~m})$ & $4.0-6.0$ \\
The Netherlands & defined based on the design vehicle swept path; $1.5-4.0$ & 1.0 \\
Germany & aprons are not constructed & - \\
Serbia & aprons are not constructed & not defined \\
Switzerland & $1.5-2.0$ & . \\
\hline
\end{tabular}

\subsection{The Splitter Island}

Splitter islands are mandatory elements of modern suburban roundabouts. They provide better control of the vehicle speed by channeling traffic flows and provide space for vertical signalization. When designing roundabouts, it is necessary to determine the space for the splitter island before defining the width of the entrance and exit lanes.

The basic functions of the splitter islands are as follows:

- Timely warning of drivers about a roundabout in the traffic network.

- Separation of traffic flows.

- Providing space for the installation of traffic signs, lighting, and other traffic equipment.

- Preventing a left turn into a roundabout.

According to [4], the use of the triangular or funnel-shaped splitter island is mandatory on suburban roundabouts. These splitter islands can be raised above the pavement by $15 \mathrm{~cm}$, or drawn, which is a more flexible solution at intersections with heavy truck traffic.

According to [5], the splitter islands must be provided on all approaches to the intersection. In addition, at roundabouts located in unfavorable topographic conditions 
(resulting in convex curves in vertical alignment or large turning angles on the approaches), it is possible to ensure the required recognizability of intersections by applying long splitter islands. The minimum width of the splitter island is $2 \mathrm{~m}$, but this guideline recommends the use of a wider island to separate the entry and exit lanes. The rounding of the top of the splitter islands is formed by a radius of at least $0.75 \mathrm{~m}$, and the distance of the island from the outer edge of the roundabout is at least $0.25 \mathrm{~m} \mathrm{[5]}$.

According to [6], raised splitter islands are used for the physical separation of entry and exit lanes on the roundabout approaches. The splitter island on the suburban roundabout is usually funnel shaped. The standard length of the island (" $\mathrm{H}$ ") is equal to the value of the outer radius of the roundabout (" $\mathrm{R}_{\mathrm{g}}$ "), as shown in Table 4. The splitter island on suburban roundabouts (where the outer radius is equal to or larger than $15 \mathrm{~m}$ ) is shifted to the left to ensure that the approach axis passes through the center point at the top of the island (point $C$, Figure 12). The minimum width of the splitter island is $2 \mathrm{~m}$, and the usual width at the entrance to the intersection (" $\mathrm{B}$ ") is equal to a quarter of the outer radius of the intersection.

Table 4. Splitter island elements according to [6].

\begin{tabular}{|c|c|c|c|c|}
\hline Outer Radius “ $\mathrm{R}_{\mathrm{g}}$ ” (m) & $\begin{array}{l}\text { Splitter Island Length } \\
\text { "H" }(\mathrm{m})\end{array}$ & $\begin{array}{l}\text { Splitter Island Width } \\
\text { "B" (m) }\end{array}$ & Shift “d” (m) & $\begin{array}{l}\text { Radius at the Top of the } \\
\text { Splitter Island " } r \text { " (m) }\end{array}$ \\
\hline 15 & 15 & 3.75 & 0.40 & 0.30 \\
\hline 20 & 20 & 5.00 & 0.45 & 0.40 \\
\hline 25 & 25 & 6.25 & 0.50 & 0.50 \\
\hline
\end{tabular}

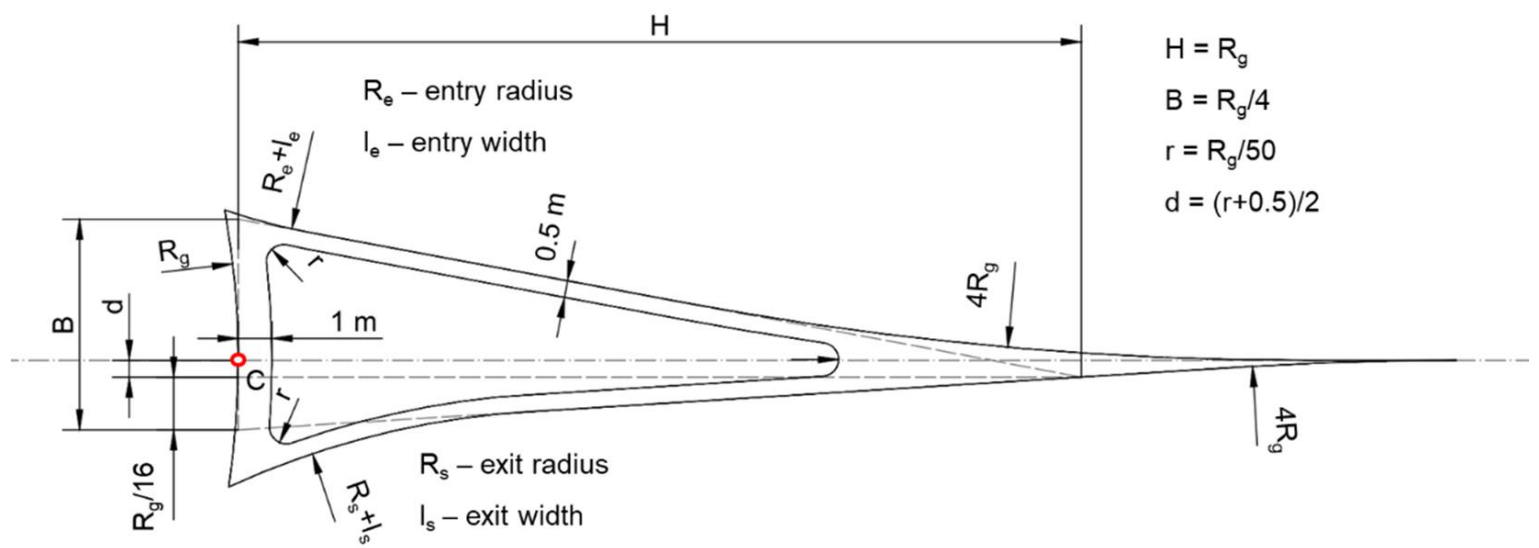

Figure 12. Splitter island elements according to [6]. The center point at the top of the island (point $\mathrm{C}$ ) is represented by the red circle.

According to $[7,8]$, splitter islands are placed on each approach to separate incoming and outgoing traffic flows. They can be raised or drawn, which is a more flexible solution at intersections with heavy truck traffic. The distance between the edge of the raised splitter island and the outer edge of the roundabout is approximately $1 \mathrm{~m}$, to improve the traffic conditions at the intersection. In terms of their layout, the splitter islands used in the Netherlands are exclusive of the radial type (Figure 13), i.e., the edges of the islands are parallel to the axis of the approach, which passes through the center of the roundabout. The advantages of such a layout are as follows:

- Entry and exit speeds are low due to provided deflection.

- The shape of the splitter island forces the driver at the entrance to the intersection to respect the right of way of the vehicle at the intersection.

- The angle between the entry lane and the circulatory roadway remains $90^{\circ}$ (which is advantageous in terms of visibility). 


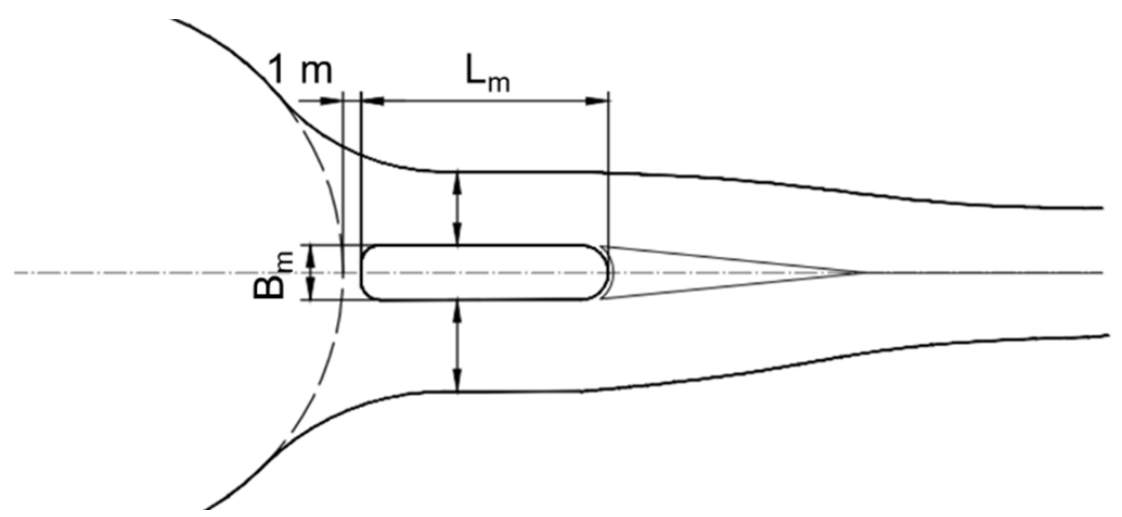

Figure 13. Radial splitter island elements for suburban roundabouts according to $[7,8]$.

The recommended length of the raised part of the splitter island at single-lane suburban roundabouts (" $\mathrm{L}_{\mathrm{m}}$ ") is 10 to $15 \mathrm{~m}$, and the standard width of the island (" $\mathrm{B}_{\mathrm{m}}$ ") is $3 \mathrm{~m}$ (Figure 13).

According to [9], the axis of the splitter island is perpendicular to the outer edge of the roundabout, with the smallest width of the island being $1.6 \mathrm{~m}$. At suburban roundabouts, funnel-shaped splitter islands are used to achieve the required lane width at the entrance to the intersection and to ensure that the curvature of the splitter island drawn edge follows the curvature of the vehicle path (Figure 14).

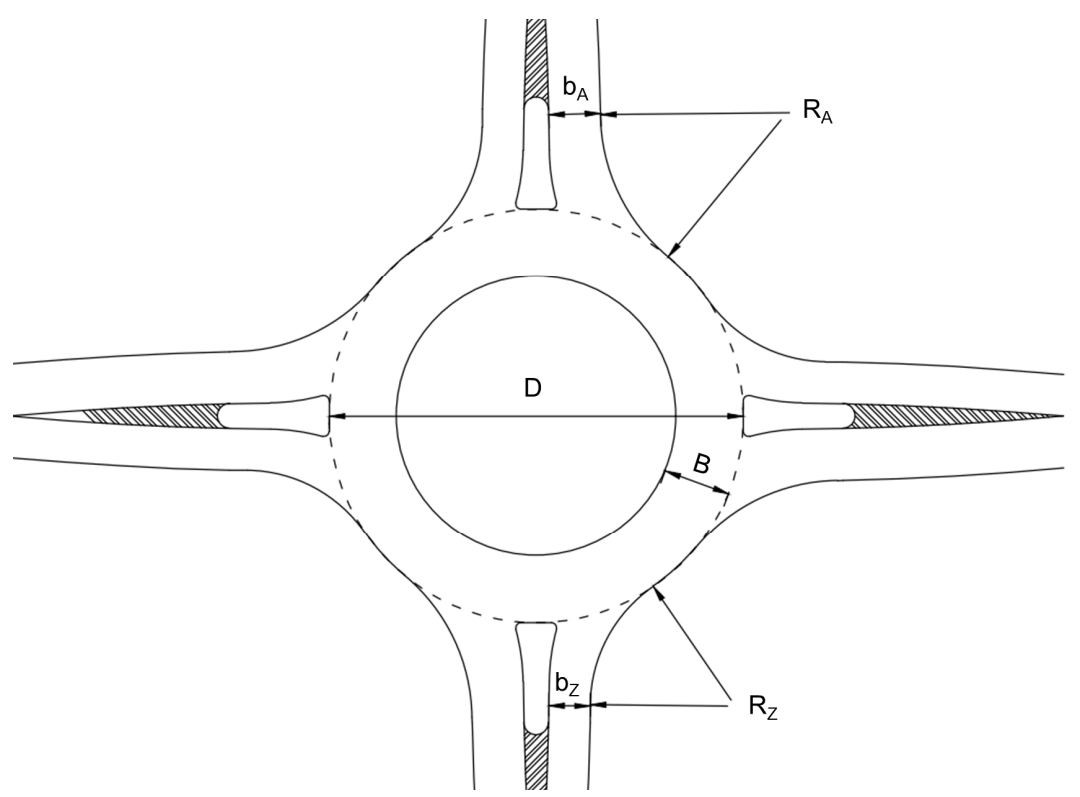

Figure 14. Funnel-shaped splitter islands on suburban roundabouts according to [9].

According to [10], the shape of the splitter island is conditioned by the desired level of traffic-flow channeling. If at single-lane roundabouts the outer radius of the intersection is greater than $20 \mathrm{~m}$ and/or the maximum design speed is equal to or greater than $60 \mathrm{~km} / \mathrm{h}$, the highest level of channeling is applied (Figure 15). A medium level of channeling (Figure 16) can be applied at a roundabout with an outer radius between 14 and $20 \mathrm{~m}$ with a maximum design speed between 50 and $60 \mathrm{~km} / \mathrm{h}$. The lowest level of channeling (Figure 17) is applied at the intersections of access roads and intersections of collector and access roads when an outer radius is smaller than $15 \mathrm{~m}$ and the highest design speed is below $50 \mathrm{~km} / \mathrm{h}$. 


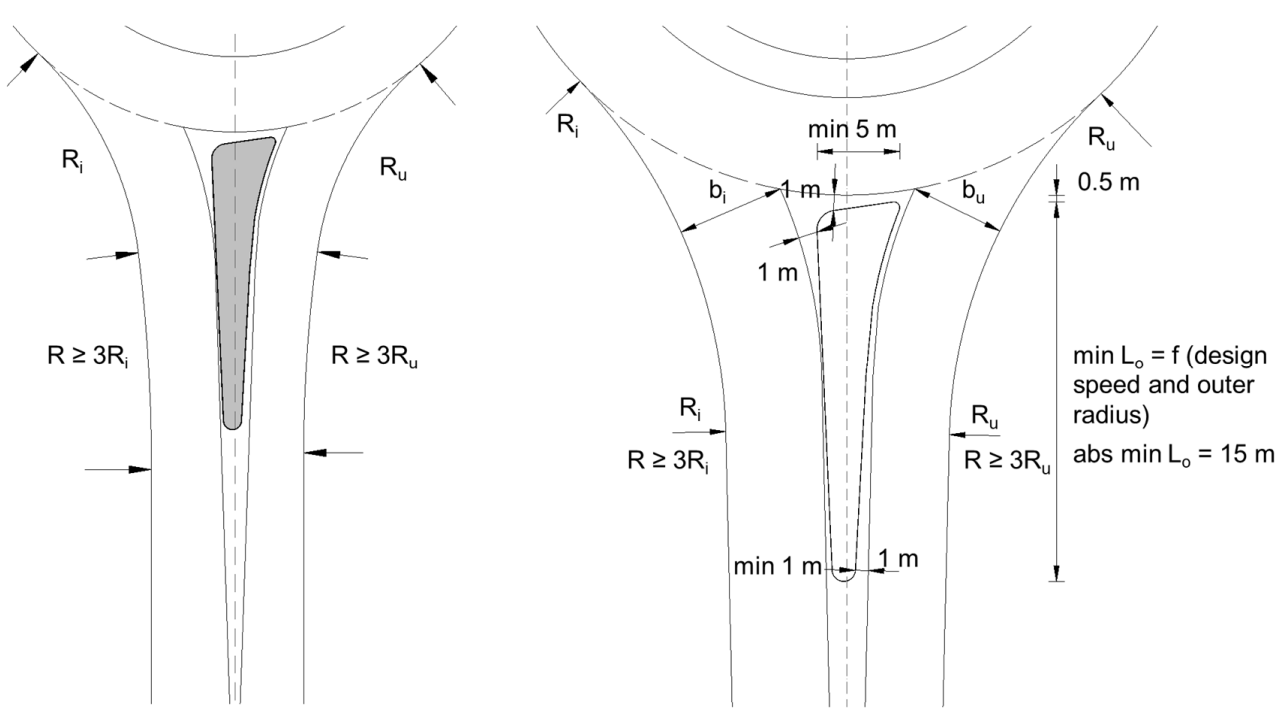

Figure 15. Splitter islands for a high level of traffic-flow channeling [10].

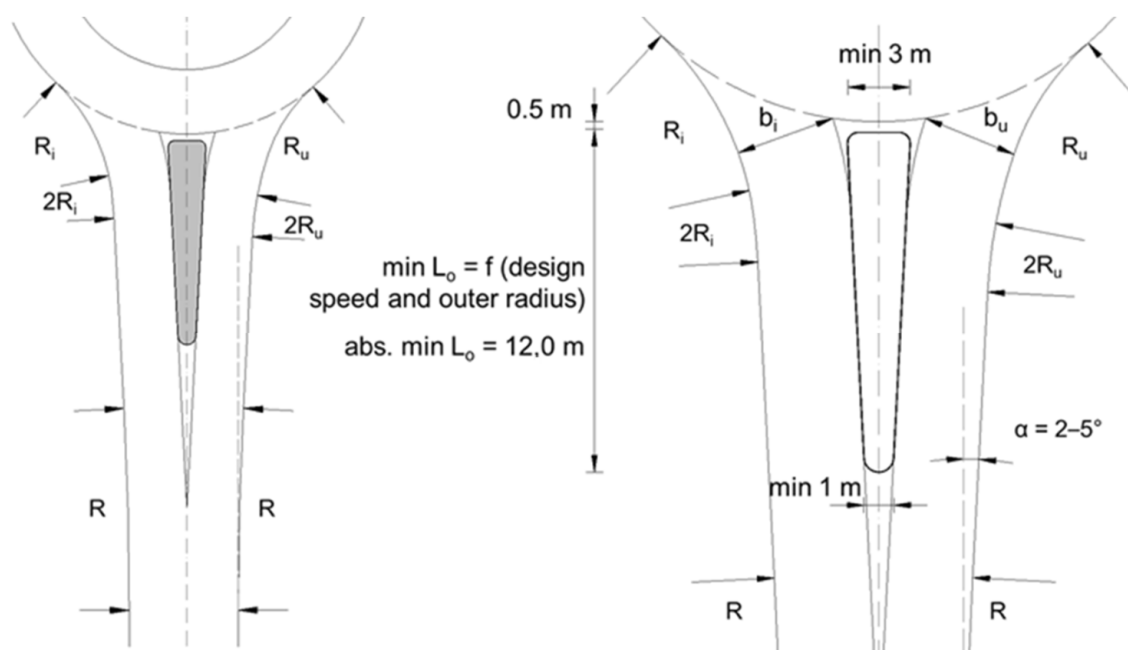

Figure 16. Splitter islands for a medium level of traffic-flow channeling [10].
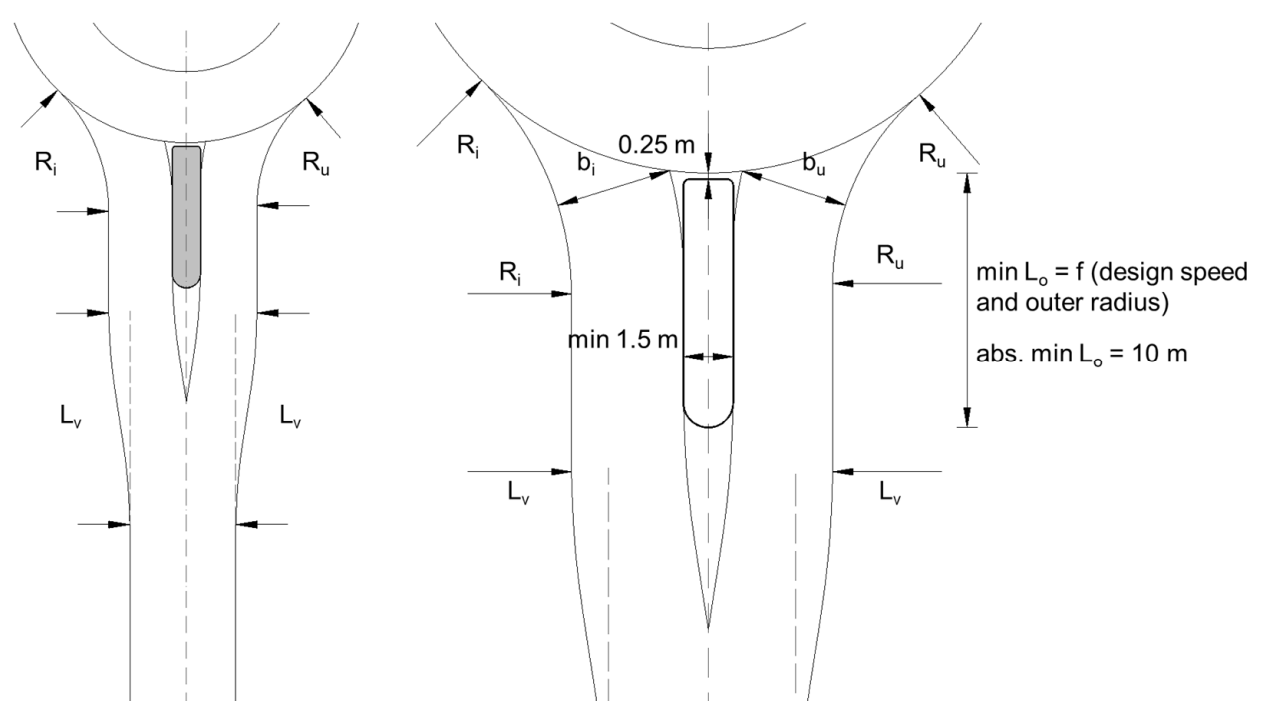

Figure 17. Splitter islands for a low level of traffic-flow channeling [10]. 
According to [12], the shape and dimensions of splitter islands depend on the widths of the entry and exit lanes, and the smallest dimensions are defined by the norm [14]. The minimum allowable width of splitter islands is $1.2 \mathrm{~m}$, and the length of the island ranges from 30 to $50 \mathrm{~m}$. A splitter island at a suburban roundabout defined according to the guidelines [15] is shown in Figure 18 - the use of funnel-shaped islands with a minimum width of $5 \mathrm{~m}$ is recommended.

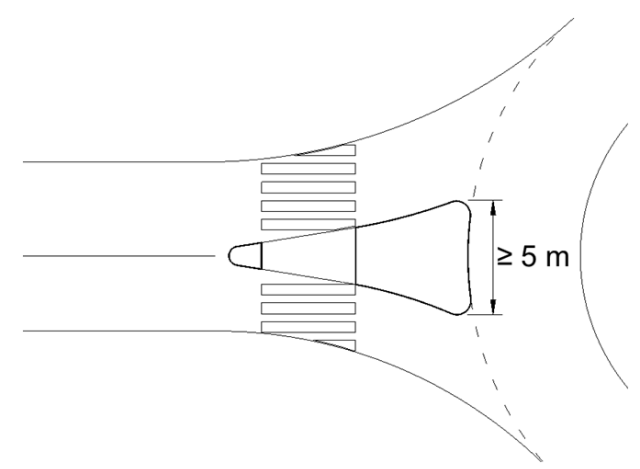

Figure 18. Splitter island according to [15].

An overview of the recommended dimensions of splitter islands listed in the considered documents is given in Table 5.

Table 5. Recommended design shape and dimensions of splitter islands according to [4-12].

\begin{tabular}{|c|c|c|c|c|}
\hline State & Splitter Island Shape & Splitter Island Length (m) & Splitter Island Width (m) & $\begin{array}{l}\text { Splitter Island Distance } \\
\text { from the Outer Edge of } \\
\text { the Roundabout (m) }\end{array}$ \\
\hline \multirow{2}{*}{ Croatia } & triangle & - & $\geq 2.0$ & $\leq 0.50$ \\
\hline & funnel & - & $\geq 2.0$ & $\leq 0.50$ \\
\hline Austria & triangle & - & $\overline{\geq} 2.0$ & $\geq 0.25$ \\
\hline France & funnel & $15-25$ & $\geq 2.0$ or (outer radius $/ 4)$ & 1.0 \\
\hline The Netherlands & radial & $10-15$ & $\geq 3.0$ & 1.0 \\
\hline \multirow[t]{2}{*}{ Germany } & funnel & - & $\geq 1.6$ & 0.0 \\
\hline & radial & $\geq 10$ & $\geq 1.5$ & 0.25 \\
\hline \multirow[t]{2}{*}{ Serbia } & triangle & $\geq 12$ & $\geq 3.0$ & 0.5 \\
\hline & funnel & $\geq 15$ & $\geq 5.0$ & $0.5-1.0$ \\
\hline Switzerland & funnel & $30-50$ & $\geq 1.2(5.0)$ & 0.0 \\
\hline
\end{tabular}

\subsection{The Entry and Exit Design}

The design of the roundabout entry and exit refers to the definition of the widths of lanes and the radius of curvature of the right edge of the pavement at the roundabout entry and exit. The widths of the entry and exit lanes are determined based on the swept path requirements of the design vehicle. Additional widening of the entry and/or exit lane, necessary to accommodate the design vehicle, is performed by rounding the right edge of the pavement or curb using one or two radii of the appropriate size.

According to [4], a prerequisite for unobstructed vehicle movement on roundabout entry and exit is a proper design of the right pavement edge and selection of the following design elements: entry and exit radii (" $\mathrm{R}_{\mathrm{ul}}$ " and " $\mathrm{R}_{\mathrm{iz}}$ "), entry and exit widths (" $\mathrm{e}$ " and " $\left.\mathrm{e}^{\prime \prime \prime}\right)$, and circulatory roadway width (" $\mathrm{u}$ "). The right pavement edge can be designed in two different ways:

1. With a shorter effective widening length (" 1 '”) —the pavement edge is composed of a circular arc and a straight line that is parallel to the side of the triangular splitter island (Figure 19a), and the selected widening (" $\left.\Delta \breve{s}^{\prime \prime}\right)$ is equal to zero;

2. With a longer effective widening length (" 1 '") —-the pavement edge is composed of a circular arc and a straight line that is not parallel to the side of the triangular splitter island (Figure 19b), and the selected value of widening (" $\left.\Delta \check{s}^{\prime \prime}\right)$ is larger than zero. 


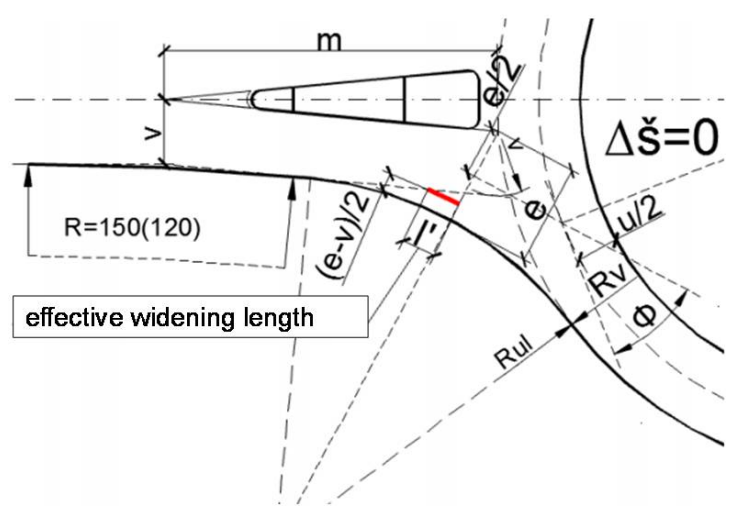

(a)

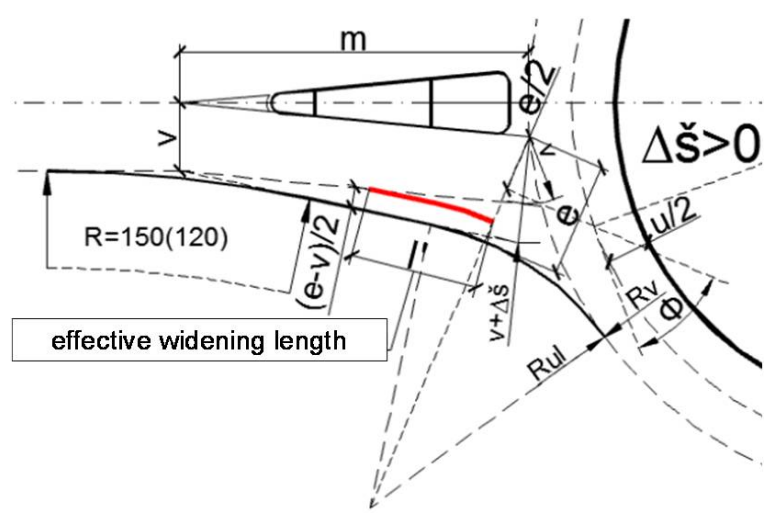

(b)

Figure 19. Entry design according to [4]: (a) shorter effective widening length and (b) longer effective widening length; " $\mathrm{v}$ " is the approach lane width, " $\mathrm{m}$ " is the splitter island length, " $\mathrm{R}_{\mathrm{v}}$ " is the roundabout outer radius, and " $\mathrm{R}_{\mathrm{ul}}$ " is the entry radius.

The designer must choose the way that will ensure unobstructed vehicle movement, and the decision must be based on the design vehicle swept path analysis. Additionally, entry design should ensure that the entrance angle (" $\Phi$ "), which is the tangent angle between the vehicle paths at the roundabout entry, is around $30^{\circ}$. In terms of the ratio between entry and exit radius, Croatian guidelines [4] recommend that the exit radius should be greater than or equal to the entry radius. The roundabout exit width (" $\left.\mathrm{e}^{\prime \prime \prime}\right)$ depends on the swept path width made by the design vehicle (Figure 20).

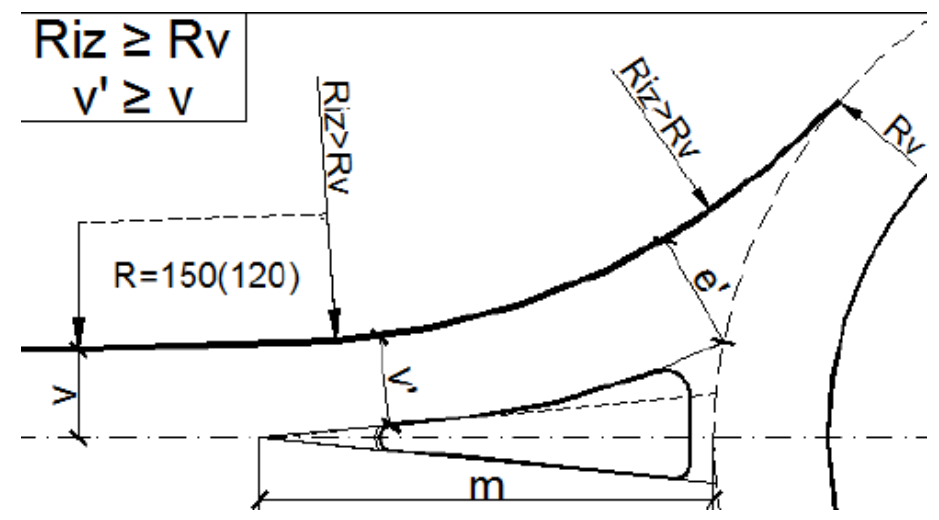

Figure 20. Exit design according to [4]: " $\mathrm{v}$ " is the approach lane width, " $\mathrm{m}$ " is the splitter island length, " $\mathrm{R}_{\mathrm{v}}$ " is the roundabout outer radius, and " $\mathrm{R}_{\mathrm{ul}}$ " is the entry radius.

According to [5], on single-lane entrances to roundabouts, the width of the entry lane along the splitter island is at least $3.75 \mathrm{~m}$. At the same time, the width of the exit lane along the splitter island is at least $4 \mathrm{~m}$. The right edge of the pavement at suburban roundabouts is rounded with a radius varying from 12 to $16 \mathrm{~m}$ at the entrance (entry radius " $\mathrm{R}_{\mathrm{E}}$ "), whereas a radius varying from 15 to $25 \mathrm{~m}$ is applied at the exit (exit radius " $\mathrm{R}_{\mathrm{A}}$ "), as shown in Figure 21. The radii at the entry are smaller than the radii at the exit to reduce the speed of vehicles at the entrance while facilitating the exit of long vehicles and buses from the intersection. The radii applied must meet the design vehicle swept path requirement.

According to [6], the recommended entry width (" $\mathrm{l}_{\mathrm{e}}$ ") at single-lane entrances, measured between the boundary lines, is $4 \mathrm{~m}$, and the entrance radius (" $\mathrm{R}_{\mathrm{e}}$ ") must always be less than or equal to the outer radius of the roundabout (" $\mathrm{R}_{\mathrm{g}}$ "). The standard values of the entry radius range from 10 to $15 \mathrm{~m}$, depending on the position of the approaches. The entry lane is bounded by boundary lines. The standard configuration of the single-lane entrance is shown in Figure 22 (for an outer radius of $20 \mathrm{~m}$ ). The width of the exit lane (" $1_{\mathrm{s}}$ ") ranges 
from 4 to $5 \mathrm{~m}$ for single-lane approaches and depends on the size of the outer radius of the roundabout (" $\mathrm{R}_{\mathrm{g}}$ "). The exit radius (" $\mathrm{R}_{\mathrm{s}}$ ") must be larger than the inner radius of the intersection (" $\mathrm{R}_{\mathrm{i}}$ "), with a minimum recommended value of $15 \mathrm{~m}$ and a maximum of $30 \mathrm{~m}$. The values of these parameters depend on the size of the outer radius of the intersection $\left(\right.$ " $\mathrm{R}_{\mathrm{g}}$ ") and are shown in Table 6.

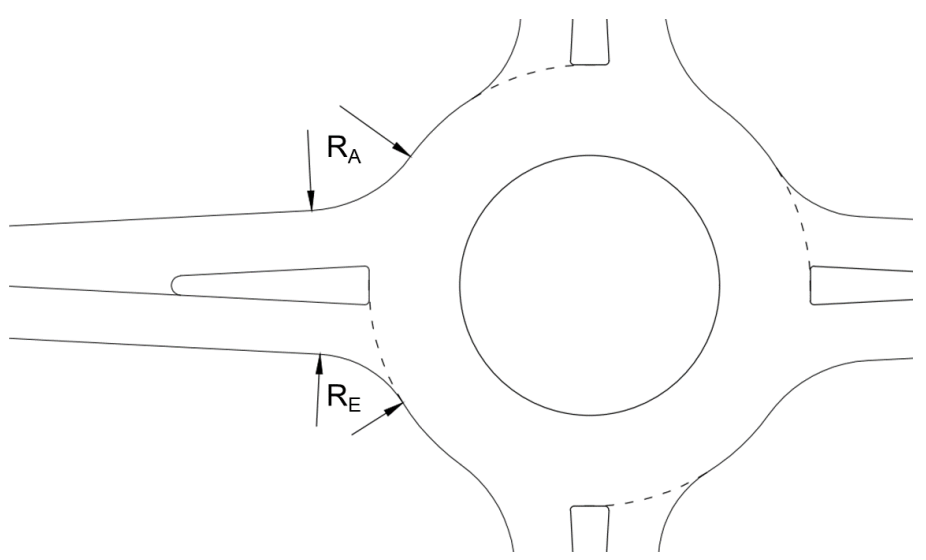

Figure 21. Right edge of the pavement at the roundabout entry and exit according to [5].

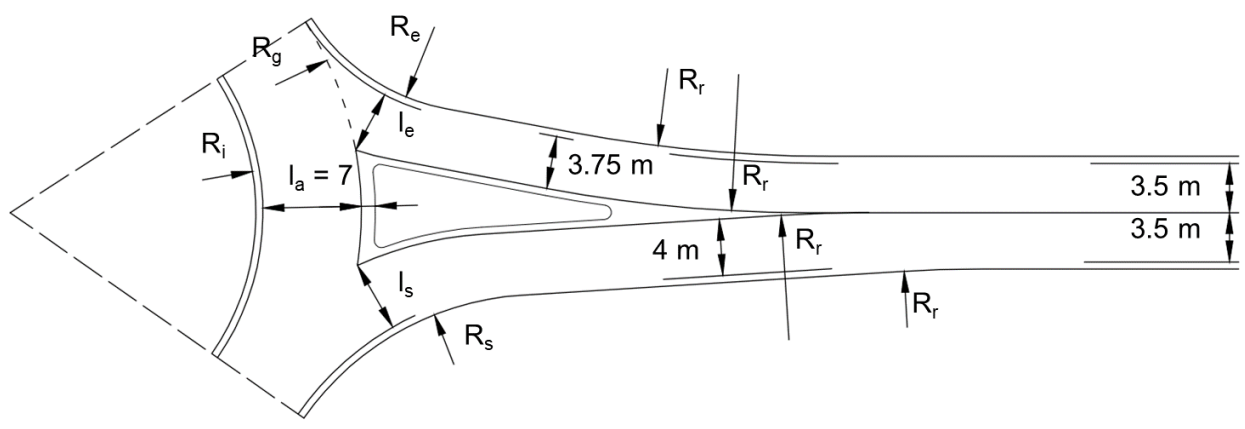

Figure 22. Single-lane approach for an outer radius of $20 \mathrm{~m}$ according to [6].

Table 6. Design elements for roundabout entry and exit according to [6].

\begin{tabular}{|c|c|c|c|c|c|}
\hline $\begin{array}{l}\text { Outer Radius } \\
\text { " } \mathrm{R}_{\mathrm{g}} \text { " }(\mathrm{m})\end{array}$ & $\begin{array}{l}\text { Entry Width } \\
\text { "1 } 1_{\mathrm{e}} \text { " (m) }\end{array}$ & $\begin{array}{l}\text { Entry Radius } \\
\text { " } \mathrm{R}_{\mathrm{e}} \text { " (m) }\end{array}$ & $\begin{array}{l}\text { Exit Width } \\
{ }^{\prime} 1_{\mathrm{s}}{ }^{\prime \prime}(\mathrm{m})\end{array}$ & $\begin{array}{l}\text { Exit Radius } \\
\text { “R } \mathbf{R}_{\mathrm{s}} \text { " (m) }\end{array}$ & $\begin{array}{c}\text { Transitional } \\
\text { Radius " } \mathbf{R}_{\mathrm{r}} \text { " (m) }\end{array}$ \\
\hline 12 & 4 & 12 & 4.0 & 15 & 48 \\
\hline 15 & 4 & 15 & 4.0 & 20 & 60 \\
\hline 20 & 4 & 15 & 4.5 & 20 & 80 \\
\hline 25 & 4 & 15 & 5.0 & 20 & 100 \\
\hline
\end{tabular}

According to [8], the widths of entry and exit lanes do not have a large impact on the speed at the roundabout but affect the accommodation of design vehicles and visibility at the roundabout. The width of the entry lanes (" $\mathrm{B}_{\mathrm{t}}$ ") should be in the range of 3 to $4 \mathrm{~m}$-wider lanes encourage drivers to drive around the roundabout at higher speeds, which reduces safety. The width of the exit lanes (" $\mathrm{B}_{\mathrm{a}}$ ") depends on the design vehicle swept path requirements, and ranges from 3.75 to $4.50 \mathrm{~m}$. The standard values of the entry radii (" $R_{t}$ ") at single-lane suburban roundabouts range from 8 to $12 \mathrm{~m}$, and the exit radii (" $R_{a}$ ") from 12 to $15 \mathrm{~m}$. Design elements of entry and exit at suburban single-lane roundabouts are given in Figure 23. 


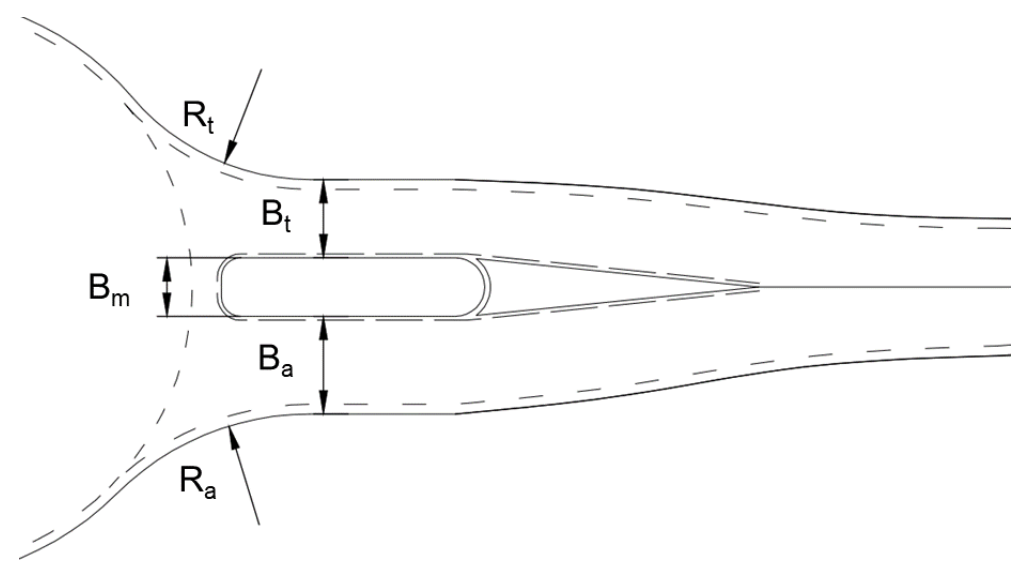

Figure 23. Design elements of entry and exit at suburban single-lane roundabouts according to [8].

According to [9], the approaches should be perpendicular to the roundabout, which is achieved by radially laying the approach axis to the outer radius of the intersection. The center of the roundabout must be as close as possible to the intersection of the approach axis. At suburban roundabouts, the recommended entry lane width in the vicinity of the splitter island (" $\mathrm{B}_{\mathrm{Z}}$ ") ranges from 3.50 to $4.00 \mathrm{~m}$, whereas the recommended exit lane width $\left(" \mathrm{~B}_{\mathrm{A}}\right.$ ") is in the range of 3.75 to $4.50 \mathrm{~m}$ (Figure 23). The rounding of the right edge of the pavement at the roundabout entry and exit lane is formed by applying a circular arc, the size of which depends on the desired speed limit and the design vehicle swept path requirements (Figure 24). The standard radius of the circular arc at the entry lane (" $R_{Z}$ ") ranges from 14 to $16 \mathrm{~m}$, whereas the radius of the circular arc at the exit lane (" $R_{A}$ ") is in the range of 16 to $18 \mathrm{~m}$. The stated values of the exit radii can be increased by $30 \%$ at suburban roundabouts (i.e., " $R_{A}$ " is in the range of 21 to $23 \mathrm{~m}$ ).

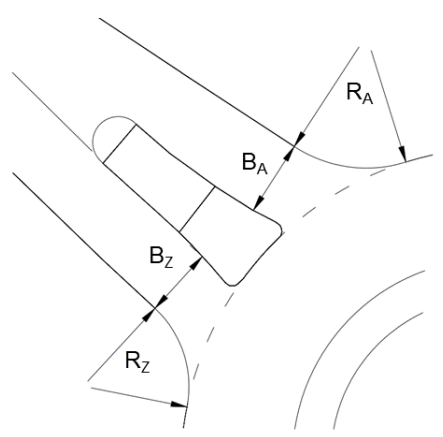

Figure 24. Design elements of roundabout entry and exit according to [9].

According to [10], the geometric elements of entry and exit are the starting point for the design vehicle swept path analysis and the definition of the roundabout design speed, thus directly affecting the capacity and safety of the roundabout. The standard width of the entry lane (" $\mathrm{b}_{\mathrm{u}}$ ") at single-lane roundabouts is 3.5 to $4.0 \mathrm{~m}$, whereas the standard width of the exit lane (" $b_{i}$ ") is 3.75 to $4.50 \mathrm{~m}$. Regardless of the required level of traffic-flow channeling, the initial condition for the entry radius (" $R_{u}$ ") is as follows: The radius (" $R_{u}+b_{u}$ ") can ultimately tangent (but not intersect) the edge of the roundabout, as shown in Figure 25. The standard values of the entry radius (" $R_{\mathrm{u}}$ ") are in the range of 12 to $16 \mathrm{~m}$. The condition of the ratio of entry and exit speeds requires that the exit radius (" $R_{i}$ ") be larger than the entry radius by $2 \mathrm{~m}$. The standard values of the exit radius are in the range of 14 to $18 \mathrm{~m}$. 


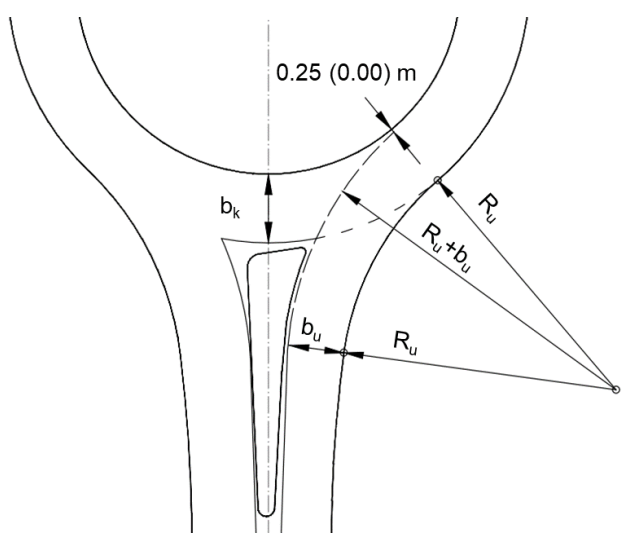

Figure 25. Initial design parameters for single-lane roundabout entry according to [10].

The number and size of the radius of curvature at the right edge of the pavement at the roundabout entry and exit and the design of the transition from the width of the approach lane to the width of the entry and exit lane depend on the desired level of traffic-flow channeling traffic.

- For the highest level of channeling, with a funnel-shaped splitter island, the rounding off the right edge of the pavement at the entry and exit of the intersection is performed using the radii " $\mathrm{R}_{\mathrm{u}}$ " and " $\mathrm{R}_{\mathrm{i}}$," whereas the transition from lane width at the approaches is performed using the radius " $R$," which is at least three times larger than " $R_{u}$ " for the entry and at least three times larger than " $R_{i}$ " for the exit.

- For a medium level of channeling, with a triangular splitter island, rounding off the right edge of the pavement at the entry is performed using radii " $R_{\mathrm{u}}$ " and " $2 \mathrm{R}_{\mathrm{u}}$ ", and rounding of the right edge of the pavement at the exit is performed using radii " $R_{i}$ " and " $2 R_{i}$." The transition from the lane width at the approach to the entry lane width is performed by applying the radius " $R$," whose tangents are a straight line that defines the edge of the pavement at the entry and a straight line parallel to the edge of the triangular splitter island and at a distance from that edge " $\mathrm{b}_{\mathrm{u}}$. "

- For the lowest level of channeling, with a radial splitter island, the rounding of the right edge of the pavement at the entry and exit of the intersection is performed using the radii " $\mathrm{R}_{\mathrm{u}}$ " and " $\mathrm{R}_{\mathrm{i}}$ ", whereas the transition from the approach lane width to the entry lane width is achieved by applying a curve of length " $\mathrm{L}_{\mathrm{V}}$. "

According to [12], a value of 3.0 to $3.5 \mathrm{~m}$ has been defined as a suitable entry lane width (" $\mathrm{b}_{\mathrm{e}}$ ") for single-lane roundabouts in terms of safety, whereas a value of 3.5 to $4.5 \mathrm{~m}$ is defined as a suitable width of the lane at the exit (" $\mathrm{b}_{\mathrm{a}}$ "). According to [12], the right edge of the pavement at the roundabout entry and exit is formed by applying two radii, as shown in Figure 26. At suburban roundabouts, the recommended size of the inner entry radius (" $R_{\mathrm{e} 2}$ ") is $12 \mathrm{~m}$, whereas the outer entry radius (" $\mathrm{R}_{\mathrm{e} 1}$ ") is five times larger. The recommended size of the inner exit radius (" $\mathrm{R}_{\mathrm{a} 2}$ ") is $14 \mathrm{~m}$, whereas the outer exit radius (" $R_{\mathrm{a} 1}$ ") is four times larger.

\subsection{The Longitudinal Slopes at Roundabouts}

Longitudinal slopes at a roundabout (longitudinal slopes of the approaches and the circulatory roadway) reflect the topography of the area.

According to [5], the longitudinal slopes of the circulatory roadway and the approaches at $20 \mathrm{~m}$ from the outer edge of the roundabout must not exceed $4 \%(2.5 \%$ if a large proportion of heavy vehicles at the intersection is foreseen). The difference between the longitudinal slope of the approaches and the cross slope of the circulatory roadway must not exceed 5\%. 


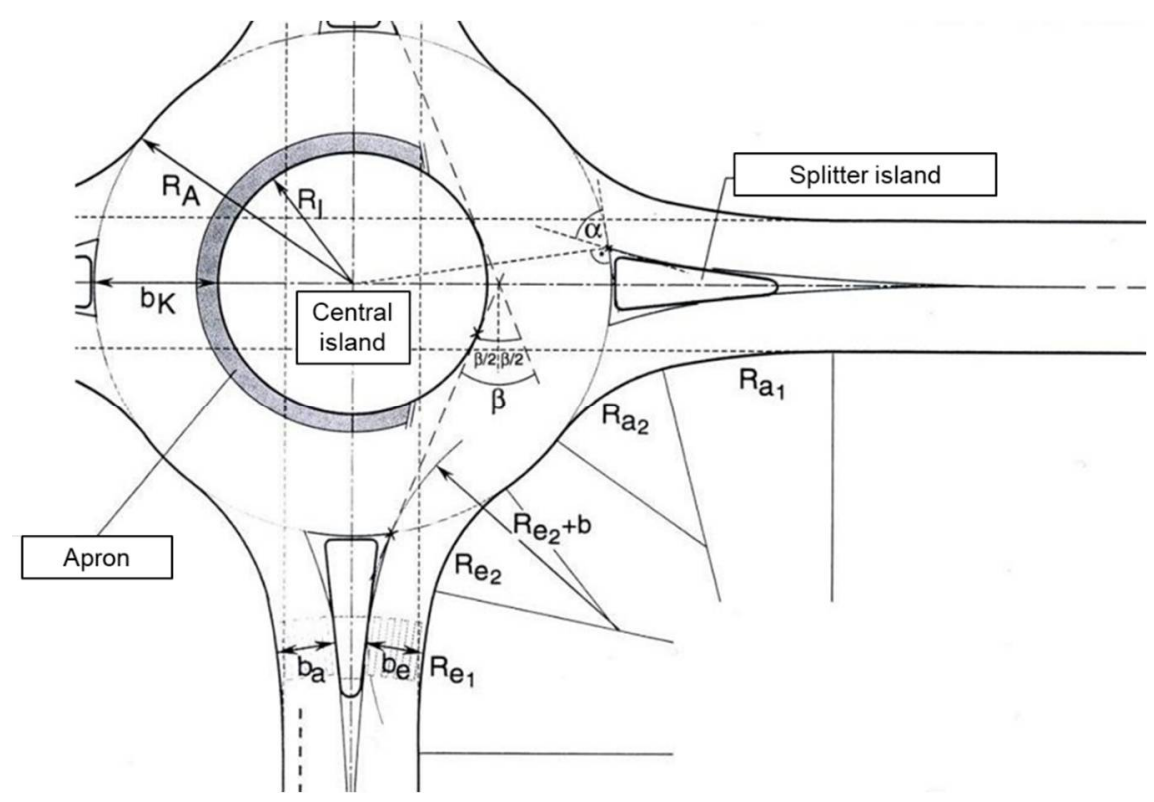

Figure 26. Design elements for single-lane roundabout entry and exit according to [12].

The recommended values for the design elements on entry and exit at suburban single-lane roundabouts listed in the analyzed documents are shown in Table 7.

Table 7. Design elements for roundabout entry and exit according to [4-12].

\begin{tabular}{ccccc}
\hline State & Entry Width $(\mathbf{m})$ & Exit Width $(\mathbf{m})$ & Entry Radius $(\mathbf{m})$ & Exit Radius $(\mathbf{m})$ \\
\hline Croatia & $4.00-7.00$ & $4.00-7.00$ & $8-20$ & $10-25$ \\
Austria & $\geq 3.75$ & $\geq 4.00$ & $12-16$ & $15-25$ \\
France & $3.75-4.00$ & $4.00-5.00$ & $10-15$ & $15-30$ \\
The Netherlands & $3.50-4.00$ & $4.00-4.50$ & $8-12$ & $12-15$ \\
Germany & $3.50-4.00$ & $3.75-4.50$ & $14-16$ & $16-18$ \\
Serbia & $3.50-4.00$ & $3.75-4.50$ & $3 \mathrm{R}_{\mathrm{u}}$ or $2 \mathrm{R}_{\mathrm{u}}$ & $3 \mathrm{R}_{\mathrm{i}}$ or $2 \mathrm{R}_{\mathrm{i}}$ \\
& & & $\mathrm{R}_{\mathrm{u}}=8-12$ & $\mathrm{R}_{\mathrm{i}}=\mathrm{R}_{\mathrm{u}}+2$ \\
Switzerland & $3.00-3.50$ & $3.50-4.50$ & $\mathrm{R}_{\mathrm{e} 1}=60$ & $\mathrm{R}_{\mathrm{a} 1}=56$ \\
& & & $\mathrm{R}_{\mathrm{e} 2}=12$ & $\mathrm{R}_{\mathrm{a} 2}=14$ \\
\hline
\end{tabular}

According to [6], the construction of roundabouts on sections of roads with longitudinal slopes of up to $3 \%$ is not considered an issue. At longitudinal slopes between 3\% and $6 \%$, instability of trucks passing through an intersection can occur. For longitudinal slopes greater than $6 \%$, it is necessary to relocate the intersection or modify the longitudinal profile of the road. Therefore, the longitudinal slopes of the roundabout approaches must not exceed 3\%.

According to [9], the longitudinal slope of the roundabout approach should not exceed $6 \%$. If the terrain slopes are higher than $6 \%$, it is necessary to place the entire surface of the intersection in one plane.

According to [10], roundabouts should be in locations where terrain slopes are less than or equal to $2.5 \%$. Longitudinal slope changes (sag or hog curves) of the approaches should be located at approximately half of the distance " $\mathrm{L}_{\mathrm{o}}$ " from the outer edge of the roundabout (Figure 27, "V $\mathrm{V}_{\mathrm{ras}}$ " is the design speed). If the longitudinal slopes of the approaches are greater than $2.5 \%$, it is necessary to mitigate them, as shown in Figure 28 .

The minimum values of the vertical hog and sag radii are determined according to the relevant speed of entry or exit. The tangent of the vertical curve should end at the edge of the circular pavement along the splitter island. Mitigation of longitudinal slopes to a value equal to or below $2.5 \%$ (Figure 28) is mandatory at all one-lane roundabouts with an outer radius equal to or greater than $20 \mathrm{~m}$ and/or when the maximum design speed is equal to or larger than $60 \mathrm{~km} / \mathrm{h}$ [10]. Mitigation of longitudinal slopes to a value 
between $2.5 \%$ and $4.0 \%$ (Figure 28) can be applied in conditions of spatial constraints at single-lane roundabouts with a design speed below $50 \mathrm{~km} / \mathrm{h}$ [10]. The highest longitudinal slopes in the roundabout zone (Figure 28) are applied only under strict spatial restrictions at intersections with an intersection design speed below $50 \mathrm{~km} / \mathrm{h}$ and low probability of occurrence of trucks and buses in the roundabout (the share of trucks and buses at the roundabout is equal to or lower than $2 \%$ ) [10].

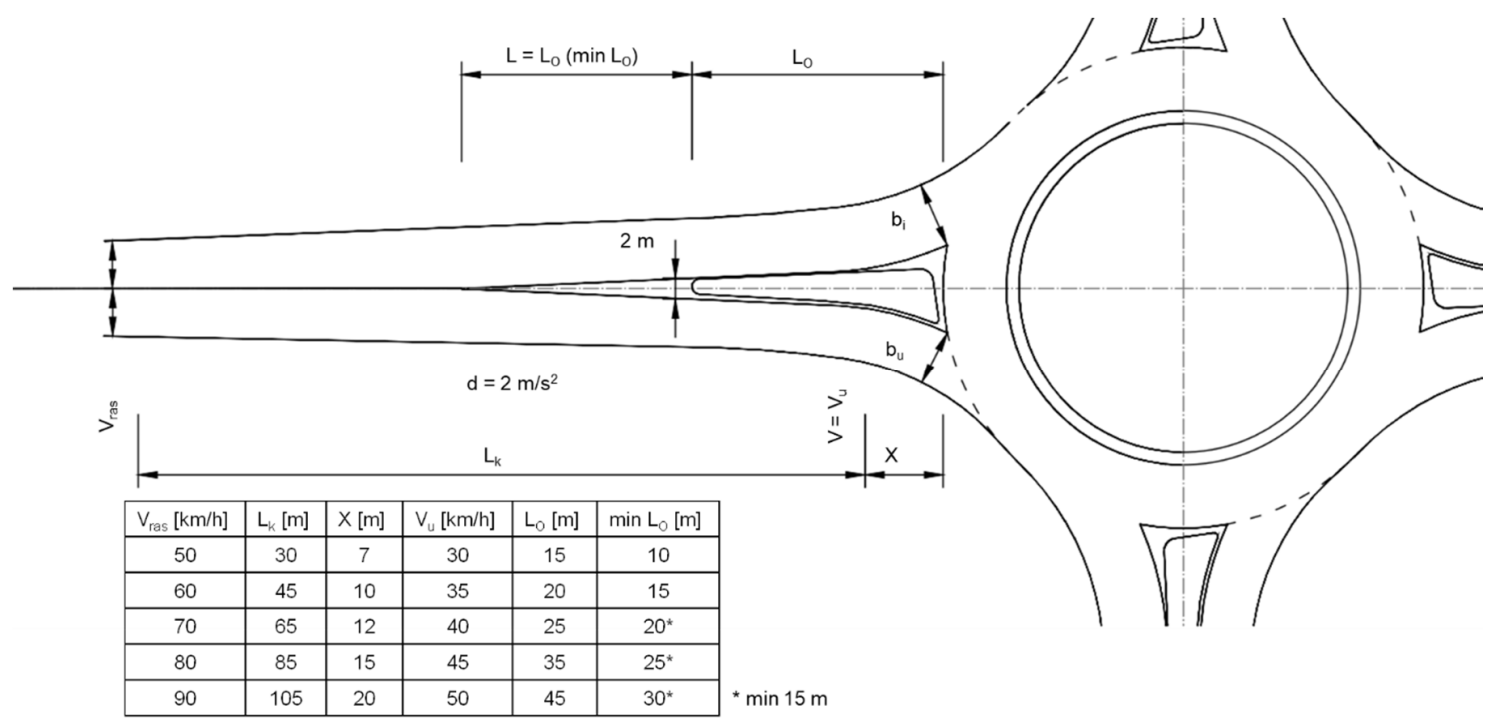

Figure 27. Roundabout approach design elements according to [10].

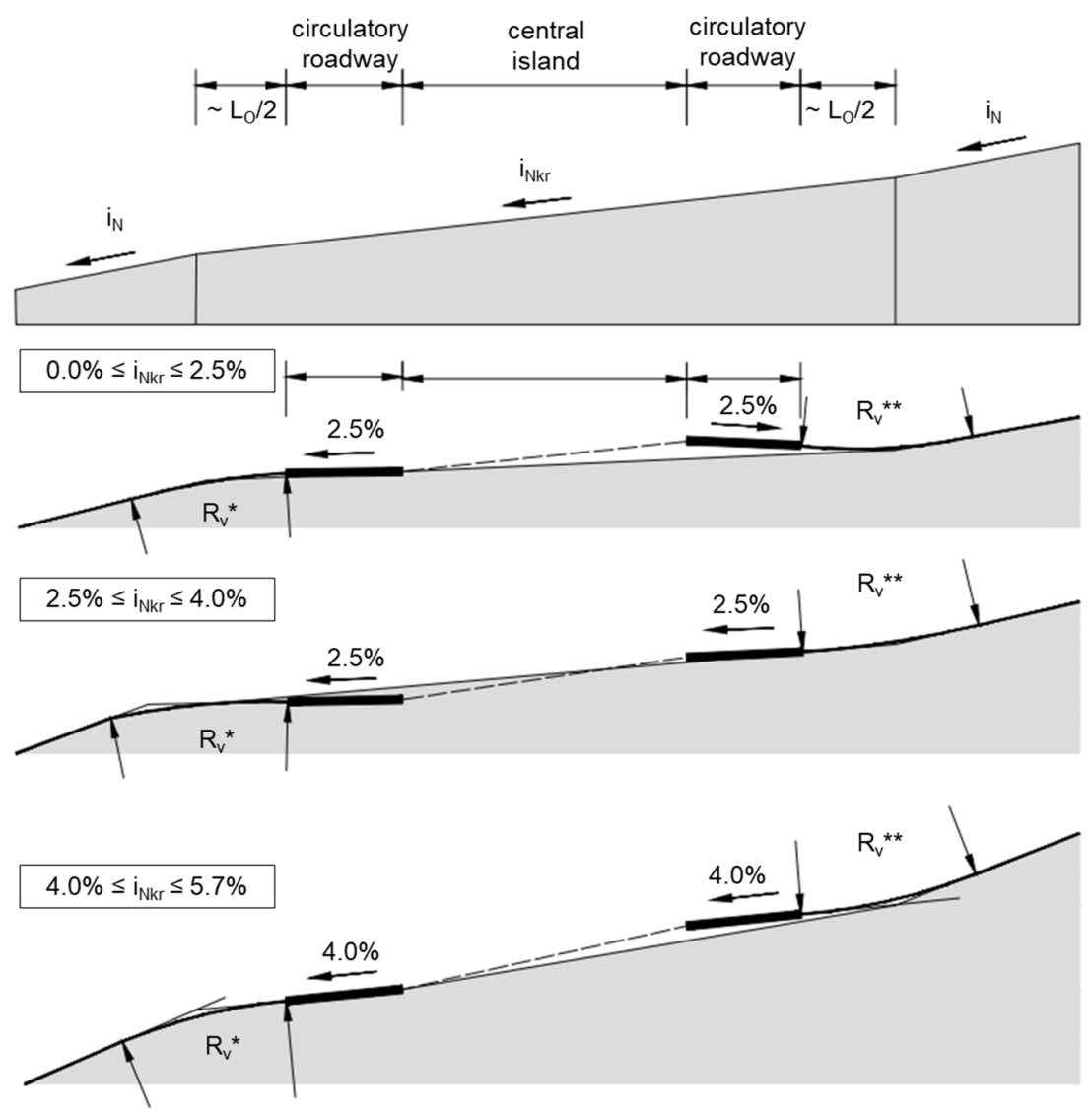

Figure 28. Mitigation of longitudinal slopes on roundabout approaches $\left(\mathrm{Rv}^{*}\right.$ - hog vertical curve radius; $\mathrm{Rv}^{* *}$ - sag vertical curve radius) [10]. 
According to [12], the intersection must be laid in one plane, the slope of which corresponds to the longitudinal and transverse slopes of the approaches. The maximum slope of the intersection surface is $5 \%$, but under demanding topographic conditions, the slope can be as high as $7 \%$. In this case, it is necessary to provide low traffic speeds at the roundabout by deflection.

The recommended values for the longitudinal slopes at roundabouts listed in the analyzed documents are shown in Table 8. According to the considered documents, in demanding topographic conditions (in hilly terrain) the entire surface of the intersection should be placed on one plane with a maximum slope of 2.5 to $7 \%$. The maximum permitted longitudinal slopes of the approaches are in the range of 3 to $7 \%$.

Table 8. Longitudinal slopes at roundabouts according to [4-12].

\begin{tabular}{cccc}
\hline State & $\begin{array}{c}\text { Maximum Slope of the } \\
\text { Intersection Plane (\%) }\end{array}$ & $\begin{array}{c}\text { Maximum Longitudinal } \\
\text { Slope of the Approaches (\%) }\end{array}$ & $\begin{array}{c}\text { Longitudinal Slope } \\
\text { Changes-Distance to the } \\
\text { Roundabout Outer Edge (m) }\end{array}$ \\
\hline Croatia & $\leq 4$ & $\leq 4$ & $\geq 6.0$ \\
Austria & $\leq 4$ & $\leq 4$ & 20.0 \\
France & $\leq 6$ & $\leq 3$ & not defined \\
not defined \\
The Netherlands & $\leq 6$ & not defined & not defined \\
Germany & $\leq 2.5-5.7$ & not defined & 7.5 \\
Serbia & $\leq 5(7)$ & $\leq 5(7)$ & not defined \\
Switzerland & & & \\
\hline
\end{tabular}

\section{Comparative Analysis}

According to the analyzed documents, the design of modern roundabout geometric elements is composed of the following steps: (1) selection of the roundabout size, (2) selection of the circulatory roadway (and apron) width, (3) selection of the splitter island shape, (4) selection of the shape and elements of the right edge of the pavement at the entry and exit, and (5) final control of the roundabout geometry.

Roundabout size is defined by the value of the outer radius. These values depend on the spatial requirements and limitations, the number and the alignment of the approaches, the traffic requirements of the design vehicle swept path, and the design speed [17-19]. The recommended values of the outer radius given in the analyzed documents range from 12.5 to $25 \mathrm{~m}$. Smaller values of outer radii are detected in Austria, the Netherlands, and Switzerland. This dissipation primarily reflects the spatial requirements and limitations, as well as the dimensions and types of the design vehicles used in the swept path analysis.

In terms of the circulatory roadway width, the main difference between the analyzed documents is the approach applied in the definition of this width, the selection of the design vehicle, and the application of the apron. Namely, according to the French guidelines, the width of the circulatory roadway is fixed and $20 \%$ larger than the widest entrance, whereas all other analyzed documents define this width according to the design vehicle swept path analysis. When defining the circulatory roadway width, Croatian guidelines recommend the use of a two-axle design vehicle, whereas types of design vehicles given in other analyzed documents that should be used in this analysis are not specifically defined.

The design of an apron on suburban roundabouts is described in Austrian, Croatian, French, Dutch, and Swiss guidelines and norms. German and Serbian guidelines do not envisage these elements in suburban locations. According to these documents, the apron width is defined based on the (long) design vehicle swept path analysis. French, Dutch, and Swiss documents recommend an apron width of at least $1.5 \mathrm{~m}$. Apron cross slopes given in the analyzed documents range from 1 to $6 \%$. Concerning the apron cross slope, one should be aware that the apron shape should deter car (and bus) drivers from crossing it, so the apron must be raised relative to the circulatory roadway and constructed with a cross slope greater than the circulatory roadway cross slope [20]. The apron also differs from the circulatory roadway in the finish layer material and/or color used. 
According to the analyzed documents, splitter islands (raised or drawn) are mandatory elements of modern suburban roundabouts. In terms of their layout, the splitter islands used in the Netherlands are exclusively of the radial type. Radial splitter islands are also given in the Serbian document-they are used for the lowest level of channeling. Other analyzed documents define the use of triangular (Croatian, Austrian, Serbian) and/or funnel-shaped splitter islands (Croatian, French, German, Serbian, Swiss) in suburban roundabouts.

Among the analyzed documents, the most elaborate approach to the design of the roundabout entry and exit is given in the Croatian guidelines. This approach is based on the design vehicle swept path analysis and therefore should result in a design that provides unobstructed vehicle movement even in the initial roundabout design. The only drawback of this approach is the fact that it can be very time-consuming [17]. The approach given in Swiss guidelines is more straightforward-additional widening of the entry and exit lane, necessary to accommodate the design vehicle, is performed by rounding the right edge of the pavement or curb using two radii of the appropriate size. According to the other analyzed documents, entry and exit lane widening is performed by rounding the right edge of the pavement using only one radius of the appropriate size.

\section{Concluding Remarks}

The documents analyzed in this entry were issued in a period of over 20 years, which was marked by the mass construction of roundabouts in their countries of origin. Even though the analysis has shown that all analyzed documents have similar design approaches for suburban roundabouts, the dissipation of the recommended and limit values of roundabout geometric elements is evident, and in some cases, even significant. This dissipation is the result of the following: (1) the differences in the geography and terrain in the countries these documents originate from, which affects the intersection design elements' dimensions and shapes, and (2) the differences in types and dimensions of design vehicles used in the swept path analysis, which is the basis for the definition of roundabout lane widths.

The following recommendations for suburban single-lane roundabouts can be given as concluding remarks for this entry:

- The roundabout outer radius must be selected by considering the spatial limitations and the requirements of the design vehicle swept path.

- The swept path analysis for the design vehicle should be the basis for the determination of the minimum required width of the circulatory roadway.

- When defining the width of a circulatory roadway at single-lane roundabouts, widths above $5.5 \mathrm{~m}$ should be avoided so that drivers do not use a wide roadway as two lanes, and so that sufficient deflection is achieved.

- When the swept path conditions for the design vehicle require a large width for the circulatory roadway, it is necessary to introduce an apron.

- The apron is intended for the passage of trucks only-buses use only the width of the circulatory roadway to ensure driving comfort.

- The design of the splitter island, i.e., the channeling of traffic flows, should depend on the traffic conditions (the main traffic flow should be undisturbed), the type of road (the road cross-section outside of the intersection zone), horizontal alignment (good visibility must be provided), and the position of intersection in the network (for suburban roundabouts, the channelization must be stretched and well signaled, otherwise raised islands can be a source of danger due to higher driving speeds).

- The entry and exit radii, along with the width of the circulatory roadway and the approach lanes, should enable the fulfillment of the design vehicle swept path requirements.

- It is recommended to use the smallest possible entry and exit radii since larger radii can result in higher speeds at the intersection.

- The exit radius should be larger than the entry radius to increase the exit speed. 
- Particular attention should be paid to wide entrances: An entry width greater than $5.5 \mathrm{~m}$ or greater than the width of a circulatory roadway can lead drivers to interpret a wide single-lane entrance as two lanes, which increases the risk of collision when entering a single-lane intersection.

To complete a modern roundabout design, a fastest path analysis and visibility checks must be conducted. If the results of these checks are not in line with the design recommendations, the geometry of the elements applied in the initial design phase must be modified. After fulfilling the conditions of the performance checks, a detailed roundabout design is conducted: the definition of signalization, lighting, and other equipment of the intersection; the final examination of the conditions of visibility; and final modification of the design elements, if necessary. This iterative process could be simplified by the introduction of the design approach that is described, to some extent, in the Croatian guidelines. Namely, these guidelines recommend that the design of the following geometric elements on suburban roundabouts be based primarily on the design vehicles swept path analyses: the outer radius, the circulatory roadway width, the apron width, and the right pavement edge at the roundabout entry and exit. This approach, which incorporates the optimization technique rather than the iterative (trial-and-error) process, could be an effective way to determine the optimal design parameters in geometric design—as similar research has shown $[18,19,21]$. With today's development of software for vehicle movement simulation that allows easier and faster construction and modification of design vehicles' movement trajectories, this could be achieved easily $[17,21]$.

Author Contributions: Conceptualization, S.A.; formal analysis, S.A.; resources, V.D.; writingoriginal draft preparation, S.A.; writing — review and editing, V.D.; supervision, V.D. Both authors have read and agreed to the published version of the manuscript.

Funding: This research received no external funding.

Conflicts of Interest: The authors declare no conflict of interest.

Entry Link on the Encyclopedia Platform: https:/ /encyclopedia.pub/13862.

\section{References}

1. Waddell, E. Evolution of Roundabout Technology-A History-Based Literature Review. In Proceedings of the Institute of Transportation Engineers 67th annual Meeting, Boston, MA, USA, 3-7 August 1997.

2. Brilon, W. Studies on Roundabouts in Germany: Lessons Learned. In Proceedings of the 3rd International Roundabout Conference, Carmel, IN, USA, 17-20 May 2011.

3. Beyondthemaps. Available online: https:/ /beyondthemaps.wordpress.com/2017/08/26/roundabouts-in-europe-2017-edition/ (accessed on 16 June 2021).

4. Smjernice za Projektiranje Kružnih Raskrižja na Državnim Cestama, Hrvatske Ceste. 2014. Available online: https: //hrvatske-ceste.hr/hr/stranice/tehnicka-dokumentacija/dokumenti/45-smjernice-za-projektiranje-kruznih-raskrizja (accessed on 16 June 2021).

5. Plangleiche Knoten-Kreisverkehre; (RVS 03.05.14); Österreichische Forschungsgesellschaft Straße-Schiene-Verkehr (FSV): Wien, Austria, 2010.

6. Aménagement des Carrefours Interurbains sur les Routes Principales, Carrefours Plans—Guide Technique; Service d'Etudes Techniques des Routes et Autoroutes, Centre de la Sécurité et des Techniques Routières: Bagneux, France, 1998.

7. CROW: Eenheid in Rotondes; CROW publication no.126; CROW: Ede, The Netherlands, 1998.

8. Roundabouts-Application and Design: A Practical Manual; (Dutch) Ministry of Transport, Public Works and Water Management, Partners for Roads: Amsterdam, The Netherlands, 2009.

9. Merkblatt für die Anlage von Kreisverkehren, K 10000; FGSV (Forschungsgesellschaft für Strassen-und Verkehrswesen): Köln, Germany, 2006.

10. Pravilnik o Uslovima Koje sa Aspekta Bezbednosti Saobraćaja Moraju da Ispunjavaju Putni Objekti i Drugi Elementi Javnog Puta, Službeni Glasnik RS, br. 50/2011. Available online: https:/ / www.mgsi.gov.rs/sites/default/files/Pravilnik\%20o\%20uslovima\% 20koje\%20sa\%20aspekta\%20bezbednosti\%20saobracaja\%20moraju\%20da\%20ispunjavaju\%20putni\%20objekti\%20i\%20drugi\% 20elementi\%20javnog\%20puta.pdf (accessed on 16 June 2021).

11. Maletin, M.; Andjus, V.; Katanić, J. Tehnička Uputstva za Projektovanje Površinskih Raskrsnica (PGS-PR/07); Građevinski Centar: Beograd, Serbia, 2010. 
12. Knoten, Knoten mit Kreisverkehr; Schweizer Norm (SN 640 263); Vereinigung Schwiezerischer Strassenfachleute (VSS): Zürich, Switzerland, 2000.

13. Kontrolle der Befahrbarkeit; Schweizer Norm (SN 640 271a); Vereinigung Schwiezerischer Strassenfachleute (VSS): Zürich, Switzerland, 1991.

14. Knoten, Knoten in Einer Ebene (ohne Kreisverkehr); Schweizer Norm (SN 640 262); Vereinigung Schwiezerischer Strassenfachleute (VSS): Zürich, Switzerland, 1999.

15. Bovy, P.; de Aragao, P.; Blanc, P.H.; Veuve, L. Guide Suisse des Giratoires; Fonds de Securite Routiere, Institut des Transports et de Planification, Ecole Polytechnique Federale de Lausanne: Lausanne, Switzerland, 1991.

16. Tolazzi, T. Alternative Types of Roundabouts; Springer: Berlin/Heidelberg, Germany, 2015.

17. Stančerić, I.; Ahac, S.; Bezina, Š.; Vlaović, F. Design limits for intersection angles between approach legs of suburban roundabouts. Građevinar 2019, 71, 389-399. [CrossRef]

18. Ahmed, H.; Easa, S.M. Multi-Objective Evaluation Model of Single-Lane Roundabouts. Transp. Res. Rec. 2021. [CrossRef]

19. Diachuk, M.; Easa, S.M. Guidelines for roundabout circulatory and entry widths based on vehicle dynamics. J. Traffic Transp. Eng. 2018, 5, 361-371. [CrossRef]

20. Montella, A.; Turner, S.; Chiaradonna, S.; Aldridge, D. International overview of roundabout design practices and insights for improvement of the Italian standard. Can. J. Civ. Eng. 2013, 40, 1215-1226. [CrossRef]

21. Ahac, S. Design of Suburban Roundabouts Based on Rules of Vehicle Movement Geometry. Ph.D. Thesis, University of Zagreb, Zagreb, Croatia, April 2014. 